\title{
EL PRESUPUESTO PROCESAL DE LA CAPACIDAD EN LAS PERSONAS JURÍDICAS, EN ESPECIAL LAS DE DERECHO PÚBLICO
}

\author{
THE PROCEDURAL REQUIREMENT OF CAPACITY IN MORAL \\ PERSONS, ESPECIALLY THOSE OF PUBLIC LAW
}

\section{JOSÉ RAMÓN GUTIÉRREZ SILVA*}

\begin{abstract}
RESUMEN: El presente trabajo pretende examinar el presupuesto procesal de la capacidad en su relación con la personalidad, particularmente con las personas morales. Tradicionalmente, la personalidad jurídica, en especial aquella de derecho público, se ha entendido como un requisito para contar con capacidad en el proceso, sin embargo, esta concepción clásica se ha visto cuestionada por realidades que prescinden de la personificación como condición tanto para el otorgamiento de la capacidad para ser parte en juicio como para actuar validamente en él.
\end{abstract}

Palabras clave: capacidad para ser parte, capacidad procesal, personalidad jurídica, entes no personificados.

ABSTRACT: The present work deals with the procedural requirement of capacity in its relation with the legal status of "personality", especially regarding juridical persons. Traditionally, personality has been understood as a capacity requirement in the judicial process; nevertheless, this conception has been questioned by the fact that sometimes personification is ignored as a condition to be a party before a court.

Key words: Aptitude to be a party; procedural capacity; juridical persons; not personified entities.

\section{LA CAPACIDAD PARA SER PARTE}

Tradicionalmente, la doctrina ha entendido que la capacidad como presupuesto procesal $^{1}$ presenta dos manifestaciones, la capacidad para ser parte y la capacidad procesal $^{2}$.

* Licenciado en Ciencias Jurídicas por la Universidad de los Andes. Profesor de Derecho Procesal de la Escuela de Derecho de la Universidad Andrés Bello. Alumno del programa de Doctorado en Derecho de la Universidad de los Andes. Correo electrónico: jgutierrez@unab.cl

${ }^{1}$ Sin perjuicio de las legítimas diferencias doctrinales que existen para delimitar los presupuestos procesales, un criterio comúnmente aceptado distingue tres grupos: $1^{\circ}$ Presupuestos procesales relativos al órgano jurisdiccional; $2^{\circ}$ presupuestos procesales relativos a las partes; y $3^{\circ}$ presupuestos procesales relativos al procedimiento. ROMERO (2006) p. 28.

2 Por todos, CORdón Moreno (1996a) p. 63, sostiene que bajo el nombre genérico de 'personalidad' se agrupa una serie de conceptos que responden a otros tantos presupuestos relativos a las partes del proceso, necesarios para que el juez pueda pronunciarse sobre el fondo del asunto. "Son por lo tanto presupuestos procesales en sentido estricto, que es preciso separar claramente para su estudio. Los dos primeros son la capacidad para ser parte y la capacidad procesal". 
La capacidad para ser parte, que algunos autores han llamado también "personalidad procesal" 3 , es un concepto que ha experimentado una interesante evolución. La doctrina ha pasado de tratar de solucionar este problema con una simple remisión al derecho material, hacia el establecimiento de un concepto autónomo, propio del Derecho Procesal.

Las posiciones más extremas llegaron a negar la relación del problema de la capacidad para ser parte con el Derecho Procesal ${ }^{4}$. Superadas estas visiones, los autores comenzaron ha centrarse en la vinculación que tradicionalmente se asigna a la idea de capacidad para ser parte con la de capacidad jurídica o capacidad de goce, reconociendo a la vez que se está frente a un problema de carácter procesal pero que tiene la particularidad de que a su respecto se recurre a los conceptos sustantivos de capacidad para encontrar sus soluciones.

Estas definiciones conceptualizan la capacidad para ser parte, así como también la capacidad procesal, desde los conceptos materiales de capacidad. Esto es, a partir de las nociones de capacidad jurídica y de capacidad de obrar o de ejercicio, respectivamente ${ }^{5}$.

Los conceptos enunciados mantienen como elemento en común el hecho de reconducir el problema a las normas propias del derecho sustantivo, sin hacerse cargo de formular una definición que intentase explicar lo que la capacidad para ser parte es en el ámbito del proceso.

Estas concepciones darán paso a formulaciones que persiguen describir lo que la capacidad es en el Derecho Procesal. Buscando independizar la capacidad para ser parte de la capacidad jurídica, aunque como veremos dicha independencia no se logra de manera absoluta. En este sentido Cordón Moreno define la capacidad para ser parte como la aptitud genérica de una persona para ser demandante o demandado en un proceso, cualquiera que este sea y aunque nunca llegue a litigar ${ }^{6}$.

\footnotetext{
${ }^{3}$ Entre otros, GUASP y ARAGONESES (2002) p. 190. Si bien el término nos parece acertado su utilización no se encuentra suficientemente difundida como para reemplazar la denominación tradicional del concepto, ello se aprecia claramente del hecho de que los propios autores que la utilizan recurren al término clásico dentro de sus explicaciones sobre la materia; también en MONTERO AROCA (1994) p. 16.

${ }^{4}$ SATTA (1971) p. 89, expresa que la capacidad para ser parte no corresponde, sino que se identifica con la capacidad de ser sujeto de derecho, y este es un problema totalmente extraño al Derecho Procesal.

${ }^{5}$ Chiovenda (1977) p. 11, expresa que la capacidad para ser parte "no es sino la capacidad jurídica llevada al proceso civil, la capacidad para ser sujeto de una relación jurídica procesal”; WACH (1977) p. 282, sostiene que "La capacidad para ser parte es un concepto derivado. Es la subjetividad jurídica de derecho privado, la capacidad para ser sujeto, activo o pasivo, de relaciones jurídicas civiles. De ahí se sigue que no habrá capacidad para ser parte cuando no haya capacidad jurídica de derecho privado, que aquella faltará en la medida que esta falte [...]"; en el mismo sentido que los anteriores, aunque sin formular un concepto, CALAMANDREI (1996) p. 362, apunta que "Estas dos nociones, a la vez contrapuestas y complementarias, se proyectan del derecho sustancial al derecho procesal: en el cual la capacidad jurídica se llama capacidad para ser parte, y la capacidad de obrar se denomina capacidad para estar en juicio o capacidad procesal".

${ }^{6}$ CORdón Moreno (1996b) p. 64. Se la ha definido también como "La aptitud para ser titular de los derechos, cargas y obligaciones que se derivan de la realidad jurídica que es el proceso", GUASP y ARAGONESES (2002) p. 189. En términos similares, MONTERO AROCA et al. (1991) p. 15; combinando los elementos de ambas definiciones: "La capacidad para ser parte es la posibilidad genérica de figurar como parte demandante o demandada en un proceso, en cualquier proceso, asumiendo la titularidad de las facultades y cargas procesales que comporta tal condición”, SAMANES (2000) p. 14.
} 
Nos parece que si bien los conceptos reseñados constituyen un avance en el sentido de independizar la capacidad para ser parte de su paralelo en el derecho material, dicha independencia no se ha alcanzado cabalmente. En efecto, en general las citadas definiciones a la hora de explicar su alcance vuelven a remitirnos a las categorías sustanciales de la capacidad recurriendo a expresiones tales como que estas coinciden esencialmente; que una es el correlativo de la otra; que están en estrecha relación; o que la capacidad para ser parte se confunde con la capacidad de goce.

No nos parece criticable esta postura. Si bien pensamos que la noción de capacidad para ser parte debe ser tratada como un concepto propio del Derecho Procesal, no se puede hablar de una plena independencia de los conceptos, es decir, debe reconocerse que efectivamente la categoría material de capacidad jurídica o de goce coincide en toda su extensión con la procesal de capacidad para ser parte.

Dicho de otra manera, no existen casos de entes que ostenten capacidad de goce y a los que se les niegue la capacidad para ser parte. Como sostienen De la Oliva y Fernández, la capacidad para ser parte está indisolublemente ligada a la subjetividad jurídica: habrá que conceder capacidad para ser parte a todos los sujetos jurídicos pues sin tal capacidad se encontrarán inermes y sus derechos e intereses podrían padecer, sin remedio alguno, incontables frustraciones. Resulta por tanto razonable que las normas generales sobre la capacidad para ser parte estén situadas donde se trata en general la subjetividad jurídica, el Código Civil, en sede de personalidad y capacidad jurídica ${ }^{7}$.

En consecuencia, pensamos que son acertadas las explicaciones que contienen elementos remisivos al derecho material siempre y cuando a la vez estas acepten que esa remisión no agota el concepto. En otras palabras, un concepto completo de capacidad para ser parte debe incorporar tanto las categorías sustanciales de capacidad como aquellas realidades que no pueden ser consideradas dentro de estas, vale decir, a aquellos entes a los que el ordenamiento jurídico ha reconocido capacidad para ser parte en juicio pero que, sin embargo, no son subsumibles bajo ninguno de los supuestos materiales de personali$\mathrm{dad}^{8}$. En este sentido estamos de acuerdo con quienes sostienen que no puede afirmarse que la capacidad para ser parte es la transposición procesal de la personalidad jurídica? .

\section{CAPACIDAD PARA SER PARTE DE LAS PERSONAS JURÍDICAS}

La capacidad para ser parte es reconocida en primer lugar y desde siempre a las personas naturales ${ }^{10}$.

\footnotetext{
7 De la Oliva y Fernández (1992) p. 425.

8 " [...] al proclamarse la igualdad jurídica de todos los seres humanos, el concepto de personalidad comienza a ser relacionado con el de capacidad, entendida esta como la aptitud para adquirir derechos y contraer obligaciones. Lentamente se irá imponiendo la idea de que en el leguaje jurídico se denomina persona a 'los seres capaces de tener derechos y obligaciones' [...]”, CORRAL (1990) p. 309.

9 SAMANES (2000) p. 13.

${ }^{10}$ Entre otros, GOLDSCHMIDT (1936) p. 192; WACH (1977) p. 283; para GUASP y ARAGONESES (2002) p. 190, si ser persona implica la capacidad o facultad de ser titular de derechos y obligaciones no sería posible que no se comprendiera también la aptitud o facultad para ser titular de los derechos y obligaciones de las partes. En consecuencia, toda persona por el solo hecho de serlo, tiene capacidad para ser parte.
} 
Con relación a las personas jurídicas, la atribución de capacidad para ser parte es asimismo indiscutida ${ }^{11}$. Lo que diferencia una de otra es que mientras las personas naturales tienen subjetividad y por tanto capacidad para ser parte en virtud de su propia naturaleza, las personas jurídicas la tienen por reconocimiento ${ }^{12}$. De esta manera la regla en esta materia es que toda persona jurídica tiene capacidad para ser parte desde que el ordenamiento la reconoce como tal ${ }^{13}$.

El principio de la plena capacidad para ser parte de las personas jurídicas tiene una de sus manifestaciones más relevantes en el Estado. Ello, por cuanto, como veremos a continuación, la personificación ha sido el pilar en el que se ha afirmado toda la construcción en torno a la aptitud del Estado para ser sometido a la jurisdicción. Es decir, la capacidad para ser parte del Estado nació y se desarrolló apoyada en su personificación.

\section{El ESTADO COMO PERSONA JURÍDICA}

Al margen de otros criterios de distinción la doctrina ha clasificado a las personas jurídicas distinguiendo entre aquellas de derecho privado y las que son de derecho público $^{14}$. La capacidad para ser parte se predica respecto de los dos tipos señalados ${ }^{15}$.

Más allá de las explicaciones que existen en torno a lo que es el Estado como realidad social y política ${ }^{16}$, abordaremos a continuación el estudio del Estado desde el punto de vista de su naturaleza como realidad jurídica, como persona jurídica.

Las primeras expresiones de una caracterización del Estado como instrumento jurídico las encontramos en el Derecho Romano bajo la idea o noción de fiscus. Este instrumento existía como un centro de referencia (como una especie de persona moral)

\footnotetext{
${ }^{11}$ La capacidad procesal de las personas jurídicas no ofrece dudas desde que en el Código Civil se les reconoce la posibilidad de ejercitar acciones civiles y criminales. MONTERO AROCA et al. (1991) p. 17; en la doctrina nacional, ANABALÓN (1946) p. 21.

${ }^{12}$ CAlamandrei (1996) p. 362, expresa que "acerca de la capacidad de ser parte (capacidad de ser sujeto de una relación procesal), poco hay que decir, el problema está en gran parte resuelto por las leyes sustanciales, que atribuyen la personalidad jurídica, no solo a las personas físicas por el simple hecho del nacimiento, sino también a las personas jurídicas, por efecto del reconocimiento [...]".

13 GUASP y ARAGONESES (2002) p. 190, sostienen que la capacidad para ser parte de las personas jurídicas es una consecuencia indeclinable del otorgamiento de la personalidad.

${ }^{14}$ Sobre este y otros criterios de clasificación de las personas jurídicas cfr. GUTIÉRREZ (1963) pp. 21 y ss.

${ }^{15}$ Las personas jurídicas de derecho público, entre otras el Estado, gozan de personalidad jurídica propia y, consiguientemente, de capacidad para ser parte en juicio, NAVARRO (1998) p. 30.

16 Para el profesor Silva BASCUÑán (2000) pp. 161 y ss., un recuento de la infinidad de teorías de lo que es el Estado resulta extenso, fatigoso y de muy poca ayuda para entender lo que este realmente es. Estima, basado en sus propias conclusiones fundadas en "[...] las fuentes revisadas y en la filosofía perenne", que "A medida que se distingue y separa la persona o personas que rigen la sociedad de las potencialidades que ponen en movimiento para hacer marchar a esta y se extiende la convicción de que no es lo mismo el poder que accidentalmente revisten quienes están dirigiendo el grupo de sus propias personas e individuales destinos, encontramos un Estado en forma, una sociedad civil perfecta. La naturaleza ha hecho su camino hasta producir la realidad de una forma asociativa que ya hemos considerado ineludible racionalmente".
} 
junto a la persona del emperador, al cual pertenecían los bienes necesarios para propender a la obtención de los fines del Estado ${ }^{17}$.

Estas primeras expresiones de una instrumentalización del Estado constituyeron un ensayo de lo que después se convertirá en el actual concepto jurídico de Estado, en su formulación como persona jurídica. Este primer ensayo serviría de antecedente para el surgimiento de la denominada "Teoría del Fisco"18, que como veremos constituye a su vez el antecedente inmediato de la personificación del Estado.

La teoría del Fisco o fiskustheorie, surgió en una etapa histórica previa a la aparición del Estado de Derecho y del Derecho Administrativo ${ }^{19}$ como una necesidad técnica para designar a una parte o faceta del Estado de la época.

En efecto, en tiempos en que aún se imponía una forma de Estado absolutista surgió la necesidad de someter al derecho a una parte de la actividad estatal. Con este fin se recurrió a lo que se llamó "la doctrina del Fisco", y que no fue otra cosa que la personificación de una parte del Estado con el objeto de someterla al Derecho y a la Jurisdicción ${ }^{20}$.

Es a partir de esta construcción técnica, previa al surgimiento del Derecho Público, que con posterioridad aparecerá la explicación del Estado como persona jurídica. Ahora como una formulación propia del Derecho Administrativo destinada a asegurar el pleno sometimiento del nuevo Estado al Derecho.

Los profesores GARCÍA DE ENTERRÍA y FERNÁNDEZ lo explican señalando que "Hacia mediados del siglo XIX, los esfuerzos dirigidos a garantizar la autonomía del nuevo Derecho Público, con la necesidad de abandonar las explicaciones personalistas y místicas del feudalismo y el absolutismo, cristalizan en Alemania con una aportación capital, sin duda tomada en préstamo del pandectismo iusprivatista: el reconocimiento del Estado como persona jurídica. El Estado sería, ante todo, una persona jurídica, y

\footnotetext{
17 En su origen la expresión fiscus describía "[...] recipientes o cestos de mimbre, donde posteriormente se guardarían monedas o dineros, sirviendo de arcas", SOTO KLOSS (1996a) pp. 194 y ss.; con anterioridad, pero sin hacer un desarrollo mayor, CLARO SOLAR había afirmado que en Roma desde un principio el Estado tuvo personalidad jurídica y que esta sirvió de modelo a todas las demás. Claro SOLAR (1927) p. 449.

18 "El instrumento de fisco usado por la cameralística germana tiene sus orígenes en el Derecho Romano [...]", Sото KLOSS (1996a) p. 194; para una completa explicación sobre la "doctrina del Fisco" o fiskustheorie, SOTO KLOSS (1996a) pp. 175 y ss.

19 Para la doctrina, el surgimiento del Derecho Administrativo está marcado por la aparición del Estado de Derecho, consecuencia de los movimientos revolucionarios liberales europeos de finales del siglo XVIII. Por todos, PANTOJA (2007) pp. 13 y ss.; aceptando esta realidad doctrinaria, GonZÁlez (1993a) p. 407, critica esta postura y ofrece una explicación que ubica el nacimiento del Derecho Administrativo en épocas muy anteriores a la Revolución Francesa.

20 GARRIDO FAlla (1994) p. 78, explica que "La doctrina del Fisco fue una construcción de los juristas del tiempo del Estado-policía, que hizo posible el sometimiento al derecho de parte de la actividad Estatal. $\mathrm{Su}$ fundamento fue la consideración de que en ciertas ocasiones los actos del Estado no se diferenciaban en absoluto de los que hubiera podido realizar un particular. Como consecuencia, se distinguió una actividad privada estatal junto a los actos de poder, estimándose que no había ninguna razón para que aquella no fuese sometida al mismo régimen de los actos particulares. Se arbitró entonces el procedimiento técnico de referir todos esos actos estatales de carácter privado a una persona jurídica, El Fisco, que para responder de ellos, podía incluso ser llevado a los Tribunales"; en el mismo sentido, SANTAMARÍa (2002) p. 367.
} 
esta constatación elemental permite iniciar, justificar y sostener la magna construcción de su comportamiento ante el derecho. La personificación jurídica del Estado se erige así -dice Geber- en el presupuesto de toda construcción jurídica del derecho público” ${ }^{21}$.

Como se ha visto, la personificación del Estado tuvo como motor principal el sometimiento de este a la jurisdicción. Afirmar su capacidad para ser parte sometiéndolo a las mismas normas que regían a los particulares. En este sentido, BALMACEDA LAZCANO expresa que el Estado es la nación jurídicamente organizada y su situación a este respecto es privilegiada frente a los particulares. Los autores desde antiguo vieron la contradicción de someter un ser así dotado a las normas que regían las relaciones patrimoniales de los individuos, de sujetarlo a los tribunales que estaban bajo su dependencia. El monarca veía con malos ojos las demandas entabladas contra el Estado para, por ejemplo, obtener el cumplimiento de un contrato. Los juristas, con el ánimo de resolver la cuestión, dijeron que el Estado en sus relaciones patrimoniales constituye una persona distinta que como poder público. Es a esta persona que le dieron el nombre de Fisco. "Las ventajas de esta doctrina son grandes. El Fisco pasaba a estar sometido al derecho privado; se le podía demandar ante la justicia; los asuntos fiscales son litigiosos. Los tribunales conquistaron mayor independencia frente al soberano. También se logró 'mayor protección jurídica para el súbdito frente a los actos soberanos de la autoridad' [...]"22.

En consecuencia, en un primer momento histórico esta personificación de una parte o faceta del Estado persiguió una finalidad netamente técnica y práctica, someter ciertas actuaciones del príncipe al Derecho y a la Jurisdicción convirtiendo en una realidad la capacidad del Estado para ser parte en juicio. Posteriormente, tras la aparición del Estado de Derecho y del Derecho Administrativo, este, inspirándose en la teoría del Fisco, adoptó la técnica de personificación para aplicarla a esta nueva concepción del Estado.

Sin embargo, la articulación del Estado como persona jurídica ha sido un tema difícil para el Derecho y muy poco pacífico para la doctrina que se ha ocupado de su estudio.

La concepción del Estado como una persona jurídica ha sido un tema de conflicto entre importantes tratadistas. Los profesores ALESSANDRI, SOMARRIVA y VODANOVIC hacen un resumen de la evolución que ha experimentado este tema en la doctrina partiendo de la base de que del hecho de que el Estado tenga un patrimonio ha surgido la cuestión de determinar si también debe tener una personalidad jurídica. Señalan que algunos autores como Duguit lo niegan, afirmando que la personalidad del Estado no existe, ni en el derecho público ni en el derecho privado, todos los derechos y obligaciones que se hacen radicar en la personalidad jurídica del Estado pueden explicarse sin inventar esa personalidad jurídica, como una cooperación de servicios públicos organizados y controlados por los gobernantes. Otros autores como Berthelemy y Ducroq esti-

\footnotetext{
${ }^{21}$ García de ENTERría y Fernández (1993) p. 26.

22 BalmaCeda (1943) p. 79.

23 AlESSANDRI et al. (2005) pp. 518 y 519.
} 
man que la personalidad jurídica del Estado solo puede ser reconocida en el campo del derecho privado, agregando que aquel, considerado como poder público, no debe ser reputado como una persona moral. Publicistas como Laband y Jellinek se inclinan por la doble personalidad del Estado, de derecho público y de derecho privado. La tendencia de hoy reconoce al Estado como persona jurídica única, con proyecciones en el campo del derecho público y del derecho privado. Para los referidos autores parece útil desde ciertos puntos de vista distinguir en el Estado dos fases de su personalidad, pero nunca se llegará a una teoría satisfactoria si no se mantiene el principio de que todos los actos del Estado deben ser considerados como de una personalidad jurídica única, que tiene diferentes órganos y manifestaciones diversas ${ }^{23}$.

En la actualidad el problema se centra en torno a si se puede hablar propiamente de una personalidad jurídica del Estado, o en realidad la personificación consiste en un instrumento meramente técnico destinado a permitir la actuación de una de sus partes o facetas -la Administración Pública- en el tráfico jurídico.

Para los profesores GARCía DE ENTERRÍA Y FERNÁNDEZ no se puede hablar del Estado como persona jurídica, sino solo de la Administración del Estado. En este contexto el Estado en su conjunto queda como una realidad superior que no se debe entender personificada. Concretamente expresan que "[...] desde el punto de vista del ordenamiento interno [en contraposición al orden internacional] no aparece en cambio, esa personalidad un tanto mística del Estado, sino solo la personalidad propiamente jurídica de uno de sus elementos: la Administración Pública"24.

El profesor GARCÍA DE ENTERRÍA a reiterado esta idea en otros trabajos afirmando que "Si la personalidad general del Estado no es sostenible en el Derecho Público, fuera del orden jurídico internacional, en donde los diversos Estados se enfrentan y se relacionan entre sí como totalidades o globalidades, hay que decir que el dogma de la personalidad jurídica cuadra perfectamente a una de las partes del Estado, a la Administración” 25 .

24 García de Enterría y FERnÁndez (1993) p. 28.

25 "La Ley y la Sentencia no son explicables, ya lo hemos visto, como productos de una entidad transpersonal y mística; en cambio, los actos administrativos, los contratos administrativos, los procesos contenciosoadministrativos, las ejecuciones administrativas no son comprensibles siquiera si no se imputasen, no ya al Estado, que es otras muchas cosas, como sabemos, y que no admite a los ojos de los juristas una determinación imprecisa, sino a la Administración como sujeto de distintas relaciones jurídicas en su amplia variedad. La Administración es una organización instrumental cuya personificación no requiere mística alguna; actúa siempre ante el Derecho como un sujeto que emana actos, declaraciones, que se vincula con contratos, que responde con su patrimonio de los daños que causa, que es enteramente justiciable ante los Tribunales. Esta realidad está personalizada como veste última de su organización, con toda evidencia. No hay en ese reconocimiento de personalidad, como bien se comprende, ninguna imaginación, ningún misticismo, ninguna explicación supraestructural de un mecanismo político que intente ocultarse; es, por el contrario, una calificación puramente técnica, un dato que hace posible su funcionamiento como lo que la Administración sobre todo es, una organización. Solo la Administración entre la diversidad de poderes del Estado se manifiesta precisamente así. Resulta con ello explicada la insalvable heterogeneidad entre la Administración y la Ley y la Sentencia, que es absurdo pretender explicar como los actos de un mismo sujeto superior, cuya excelsa eticidad pueda producir las decisiones más altas del Derecho, según los dogmas hegelianos”. GARCÍA DE ENTERría (1992) p. 200. 
Para este autor, detrás de la concepción del Estado moderno como una persona subyace una concepción absolutista del mismo. En el fondo se trataría de un resabio de una concepción de la sociedad en torno a un centro subjetivo, lugar que era ocupado por el monarca pero que no tendría cabida en la actual configuración del Estado ${ }^{26}$. En consecuencia solo sería posible hablar de una personalidad jurídica de la Administración del Estado.

Frente a esta postura se encuentra la doctrina que no ve inconveniente alguno en hablar de una personalidad jurídica del Estado. Santamaría Pastor, junto con declarar que esta es "la línea de opinión común de la doctrina Europea"27, formula una crítica a la primera posición planteada centrándola en la falta de explicación que esta ofrece para toda aquella actividad estatal que no consiste en administrar, apunta que la crítica fundamental que cabe formular a esta posición radica en que olvida (u omite) que en el Estado coexisten junto a la administración estatal, un conjunto de órganos constitucionales dotados de personal y bienes propios, y que se mueven en el tráfico jurídico con absoluta independencia de la Administración del Estado, Para el autor, "negar la personificación del Estado en su conjunto, limitándola a su administración, supone dejar en un extraño terreno de nadie a esos órganos que, al no pertenecer a persona jurídica alguna, carecerían de toda posibilidad de actuación autónoma en el campo jurídico. Por ello, la personificación del Estado es la única solución que no plantea problemas prácticos. El ente político primario en el nivel estatal, es, pues, el Estado mismo, entendido este como el conjunto de todas las organizaciones públicas de ámbito nacional" 28 .

Dentro de esta misma línea de opinión, Garrido Falla se muestra partidario de reconocer la personalidad única del Estado como una manifestación jurídica del Estado en su conjunto: administración, legislatura y jurisdicción, aunque reconociendo la evidente identificación que en la práctica se produce entre el Estado persona jurídica y la Administración ${ }^{29}$.

26 "Es evidente que esta construcción no tiene ninguna relación con la anterior. Subyace en ella visiblemente un componente hegeliano, que pretende sustantivar la totalidad del Estado como un 'espíritu objetivo' transpersonal que vendría a sustituir el tradicional, y ya visto como arcaico, centro subjetivo del monarca, y que a la vez elude sabiamente la posición exacta del pueblo en el sistema", "Desde esta base se comprende que no tenga cabida la idea de una voluntad atribuible a un ente abstracto, Estado, que vendría a ser el ordenador de la sociedad y del Derecho, que era lo que el viejo dogma de la personalidad del Estado presentaba e intentaba justificar, desde concepciones absolutistas subyacentes y solo conceptualmente travestidas". GARCÍA DE ENTERria (1992) p. 198.

27 También en este sentido, GONZÁLEZ (1994b) p. 226, declara que "Según la doctrina tradicional, la personalidad es, junto a la soberanía, elemento definidor del Estado jurídicamente considerado”.

28 SANTAMARÍA (2002) p. 374.

29 “'Hay que advertir que tampoco aquí nos encontramos ante un fenómeno de doble personalidad (personalidad del Estado y personalidad de la Administración): La personalidad jurídica del Estado es única y se refiere, desde luego, al conjunto de sus funciones'. Lo que ocurre es que, desde el punto de vista del derecho interno, la doctrina de la personalidad estatal tiene su relevancia práctica normalmente en cuanto personalidad de la Administración pública, pues es esta la que aparece como titular de los bienes de Estado, la que dispone de los que el Estado pueda heredar (art. 956 del Código civil), la que contrata con los particulares, la que responde civilmente por la gestión de los servicios públicos y la que es demandada ante los Tribunales civiles o contencioso-administrativos”. GARRIDO FALla (1994) p. 318; la misma opinión ha manifestado el autor en otras publicaciones en las que se expresa prácticamente en los mismos 
Entre la doctrina nacional, el desarrollo de la idea de la personalidad jurídica del Estado ha sido pacífico. No todos los autores han acusado recibo de esta polémica y no se observa en nuestro medio una militancia dogmática por una u otra postura. La actitud mayoritaria apunta a dar por supuesta la personalidad jurídica única del Estado ${ }^{30}$.

Don Luis Claro Solar, refiriéndose a las personas jurídicas, afirma categóricamente la personalidad jurídica única del Estado ${ }^{31}$.

Los profesores Aylwin y Azócar Brünner dan por supuesta la personalidad única del Estado sin entrar a describir, calificar ni confrontar las posturas que se plantean en la doctrina comparada. Señalan que "[...] En las relaciones políticas y de poder, la Nación jurídicamente organizada se llama Estado; en cambio, en sus relaciones patrimoniales, la Nación jurídicamente organizada recibe el nombre de Fisco (expresión que proviene de la voz 'fiscus', cesto del príncipe). Estado y Fisco son dos denominaciones que se le dan a una misma persona jurídica, que es siempre de derecho público" 32 .

El profesor Silva Cimma hace una descripción breve y solo de carácter general de una "Teoría sobre la doble personalidad del Estado", enfocándose en señalar aquellas doctrinas que hablan de una personalidad de derecho público cuando actúa el Estado como poder, y una de derecho privado cuando actúa como persona jurídica. Lo concreto es que el autor da por superadas estas doctrinas para hablar de una personalidad única del Estado y exclusiva de Derecho Público ${ }^{33}$.

En el mismo sentido se pronuncia el profesor Soto Kloss cuando expresa, a propósito de las relaciones entre Estado y Derecho, que "Al conceptualizar al Estado como persona jurídica se da un paso gigantesco en la configuración de esta relación Administración-Derecho, ya que se enfoca al Estado desde una visión jurídica propiamente tal y con las técnicas y mecanismos propios de la ciencia de Derecho" 34 .

términos; "En resumen: reducir la personalidad del Estado a la de la Administración no significa otra cosa que reducir la teoría a la práctica: si los actos del Estado que había que someter al Derecho y a la fiscalización jurisdiccional eran actos administrativos; si los contratos del Estado se concluían a través de sus órganos competentes -que pertenecían a la Administración pública- y si las herencias que recibía el Estado, la administración de su patrimonio y la propia titularidad de los bienes y derechos de la Hacienda pública, se gestionaban por la Administración pública, resulta comprensible que se terminase por olvidar la personalidad del todo (el Estado), dado el protagonismo de su parte más significativa (la Administración)”, GARRIDO FALLA (1982) p. 16.

30 Sobre la aceptación en la doctrina y jurisprudencia nacionales del carácter subjetivo de la Administración del Estado, vid. PANTOJA (1998) p. 108. Cabe precisar que el autor omite aludir a la personalidad jurídica del Estado en su conjunto limitando su exposición a la personificación de la Administración del Estado.

31 Claro SOlar (1927) p. 449.

32 AYLWIN y AZÓCAR (1996) p. 179.

33 Señala el autor que "La verdad es que la teoría sobre la doble personalidad del Estado ha sido definitivamente abandonada por la doctrina científica, que inviste hoy en día al Estado de una personalidad única y exclusiva de Derecho Público, sea que celebre actos potestativos sometidos al derecho Público por entero, sea que lo haga en el orden del derecho común. Lo que pasa es que en este segundo evento, no necesita simplemente colocarse frente a los administrados en un plano de desigualdad jurídica, pero no por eso pierde su personalidad jurídica”. Silva Cimma (1995) p. 138.

34 Soto KLOSS (1996a) p. 170. 


\section{LA CAPACIDAD DEL ESTADO PARA SER PARTE}

Los argumentos esgrimidos por la doctrina para afirmar la personalidad jurídica del Estado y su Administración tienen como elemento común la circunstancia de que esta se estima, tanto en su concepción histórica como en su posterior desarrollo, como una creación técnica elaborada por el Derecho con el único propósito de someter al Estado y su Administración al Derecho y a la jurisdicción. Como expresa Soto Kloss, "la fundamentación jurídica del principio de juridicidad esta dada en nuestro Derecho por el hecho de ser el Estado una persona jurídica"35.

En consecuencia, la personificación del Estado surgió como consecuencia de la necesidad de afirmar la aptitud del Estado para ser demandante y demandado en juicio. Su capacidad para ser parte, capacidad que hoy no es discutida. Como sostiene Juan Sánchez, con independencia de las normas materiales, la capacidad para ser parte de las entidades de derecho público no es discutida cualquiera sea el orden jurisdiccional competente para ejercer el control sobre ellas. Dicha capacidad es la traslación del concepto de personalidad jurídica al terreno procesal ${ }^{36}$.

En este sentido expresa Ariño que el proceso de personificación del Estado tuvo una clara finalidad de limitación del poder, de sometimiento jurídico del imperium y es un fenómeno que se inserta en el más amplio proceso de juridificación del Estado ${ }^{37}$.

En este aspecto la doctrina ha entendido que el Estado y su faceta más preponderante para estos efectos, la Administración, son solo un sujeto más y que está sometido a las mismas normas que los particulares. Así, para Balmaceda Lazcano la teoría más aceptable entiende que el Estado es una persona jurídica única que despliega su acción en diversas esferas y con diversos derechos. Tiene una capacidad para ejercer derechos de potestad pública. En este sentido, su situación es de superioridad frente a los particulares, privilegiada; está fuera del derecho común. Pero junto a ella esta su aptitud privada para ser titular de derechos y obligaciones patrimoniales. En este aspecto esta en igualdad con los individuos, y se sujeta a las reglas de la ley general ${ }^{38}$.

En concordancia con esta opinión, el profesor Vodanovic introduce un interesante matiz que a nuestro juicio la provee de un mayor realismo. Señala que cuando el Estado realiza actos de soberanía queda regido por el Derecho Público y en tal caso actúa en un plano de superioridad con respecto a los individuos, y cuando actúa en el campo del Derecho Privado queda sometido a las normas de este y actúa, en principio y salvo excepciones expresas, en un plano de igualdad con los particulares ${ }^{39}$.

Evidentemente el matiz de realidad que introduce el profesor Vodanovic esta dado por el reconocimiento de situaciones de excepción al principio de igualdad entre Estado

\footnotetext{
35 SOTO KLOSS (1996b) p. 154.

36 JUAN SÁNCHEZ (1998) pp. 133-134.

${ }^{37}$ La doctrina buscaba la sujeción del poder en cuanto a tal y la construcción de un régimen general de responsabilidad sin recurrir a las ficciones de la teoría del Fisco, ARIÑO (1970) pp. 94-96.

38 BALMACEDA (1943) p. 78.

39 VODANOVIC (2003) p. 277.
} 
y particulares. La actuación del Estado en el ámbito patrimonial, si bien se encuentra regida por los principios de igualdad ante la ley y de igual protección de esta en el ejercicio de los derechos, tiene elementos que quiebran dicha igualdad. Vale decir, el Estado, por el mero hecho de serlo, recibe un tratamiento especial por parte del ordenamiento jurídico en diversos ámbitos de actuación, tanto extrajudicial ${ }^{40}$ como judicial, lo que muchas veces deriva en un tratamiento especial o privilegiado para su posición de parte, como ocurre por ejemplo en el caso de art. 751 del Código de Procedimiento Civil que dispone la consulta obligatoria de toda sentencia definitiva no apelada pronunciada en primera instancia en juicios de hacienda cuando sea desfavorable al interés fiscal $^{41}$.

Si bien la personificación ha significado el sometimiento definitivo del Estado tanto al derecho como a los medios establecidos para su tutela, desde un punto de vista cuantitativo resulta indudable que este fenómeno adquiere su mayor significación cuando lo llevamos a la faceta más relevante del Estado para estos efectos, su Administración.

\section{LA ADMINISTRACIÓN DEL ESTADO COMO PERSONA JURÍDICA}

Tal como hemos visto, si bien existen algunas divergencias en la doctrina en lo relativo a la personalidad jurídica del Estado, ellas no alcanzan a la personificación de su Administración. Nuestro ordenamiento jurídico hace un reconocimiento ${ }^{42}$ explícito a la personalidad jurídica del Estado y de la Administración, el que ha sido calificado por profesor Soto Kloss como la aparición de la personificación en nuestro ordenamiento organizativo público ${ }^{43}$.

40 Claro ejemplo de este tratamiento especial es lo dispuesto por la Ley No 19.886 de 2003. En los contratos que celebre la Administración del Estado a título oneroso, para el suministro de bienes muebles y de los servicios que se requieran para el desarrollo de sus funciones, la licitación pública será obligatoria cuando las contrataciones superen las 1.000 unidades tributarias mensuales salvo que en la respectiva licitación no se hubieren presentado interesados, en tal situación procederá primero la licitación privada y en caso de no encontrar nuevamente interesados será procedente el trato o contratación directa, pero las bases que se fijaron para la licitación pública deberán ser las mismas que se utilicen para contratar directamente o adjudicar en licitación privada (Arts. 1, 5 y 8).

${ }^{41}$ Esta institución ya era criticada por algunos de los primeros comentaristas de nuestro Código de Procedimiento Civil: "Tiene el Fisco privilejios que no se avienen con los principios de igualdad. No se ha creido bastante seguro el patrocinio fiscal, que tiene a su servicio un cuerpo de abogados i toda la maquina administrativa, como elemento de defensa, cuando todavía se entrega esta a los tribunales de alzada, desnaturalizando sus funciones, i se encarga a la lei que apele por él”, TORO y ECHEVERRía (1902) p. 702.

42 Hablamos de reconocimiento en oposición a creación legal de la institución, lo que provendría de la influencia que tuvo Savigny en nuestra codificación civil, en este sentido Andrés Bello recogió la idea de este autor en torno a que existen personas jurídicas cuya existencia es natural o necesaria y que por tanto no necesitan de aprobación de la autoridad o de consagración legal expresa, dentro de estas se encuentran las de Derecho público que se mencionan en el art. 547 del Código Civil. Hanisch (1980) p. 174; con anterioridad a este autor, ClARO SOlAR ya había afirmado de manera clara la influencia que tuvo Savigny en Bello con relación a este punto, cfr. Claro Solar (1927) p. 447.

${ }^{43}$ ReYeS y SOTO Kloss (1980) p. 19. 
Concretamente es en el inciso segundo del art. 547 del Código Civil donde expresamente se reconoce la personalidad jurídica del Estado ${ }^{44}$. Aunque si consideramos la afirmada personalidad única del Estado la norma parece incurrir en un error al distinguir entre este (al que llama Nación) ${ }^{45}$ y el Fisco como personas jurídicas distintas.

No obstante que la personalidad jurídica única del Estado se encuentra ampliamente aceptada por la doctrina, los profesores Alessandri, Somarriva y Vodanovic ofrecen una interesante explicación para este doble señalamiento del Estado (Nación y Fisco) en el artículo 547 del Código Civil. Este se debería a la influencia de la teoría dualista que imperaba antes y en virtud de la cual el Fisco era una persona distinta del Estado. Señalan además que actualmente también se puede encontrar justificación para aquella doble mención. Ella resultaría de una intención de enfatizar las dos capacidades de la personalidad única del Estado, la de derecho público y la de derecho privado. Lo que también parece reflejarse en leyes de nuestros días como la del Consejo de Defensa del Estado (CDE) que atribuye a este la defensa del Fisco y la defensa del Estado (art. 3 No 1 y No 2 D.F.L. No 1 de 1993) ${ }^{46}$.

En el plano terminológico, tanto en nuestra legislación como en nuestra doctrina se encuentra ampliamente difundida y aceptada la utilización del término "Fisco" cuando lo que se busca es referir al Estado en su faceta Administrativa. En efecto, la noción de Fisco en nuestro ámbito jurídico no se identifica con la idea histórica que la doctrina señala en los orígenes de la moderna noción de Estado de Derecho, sino que se asocia con la Administración del Estado ${ }^{47}$. Ahora bien, se hace necesario precisar esta afirmación. Debemos determinar cuál es el alcance de la noción de Fisco en la estructura administrativa chilena. Ello es importante por cuanto, si bien hoy no existen dudas en torno a la plena capacidad del Estado para ser parte, resulta necesario determinar cómo se manifiesta en el terreno práctico esta capacidad, y para esto es necesario considerar el ámbito de influencia de la personalidad jurídica del Fisco dentro del esquema organizativo de la administración, como es también necesario precisar cuál es la importancia efectiva que esta personalidad tiene para materializar la capacidad del Estado en el proceso.

\footnotetext{
${ }^{44}$ La norma citada, refiriéndose al ámbito de aplicación del Título XXXIII del Libro I ("De las Personas Jurídicas") dispone: "Tampoco se extienden las disposiciones de este título a las corporaciones o fundaciones de derecho público, como la nación, el fisco, las municipalidades, las iglesias, las comunidades religiosas, y los establecimientos que se costean con fondos del erario: estas corporaciones y fundaciones se rigen por leyes y reglamentos especiales".

45 "Es indudable que el inciso $2^{\circ}$ del Art. 547 del Código Civil se refiere al Estado cuando cita la nación entre las personas jurídicas de derecho público: da a la última palabra el significado de la primera. Don Andrés Bello hacía sinónimas ambas expresiones. En sus Principios de Derecho Internacional [En nota al pie No 17: París, 1882 (cuarta edición), p. 23, No 1] manifiesta que 'nación o Estado es una sociedad de hombres que tienen por objeto la conservación y felicidad de los asociados, que se gobierna por leyes positivas emanadas de ella misma y es dueña de una porción de territorio'. Como se ve, el redactor de nuestro Código Civil define propiamente el Estado, que considera sinónimo de nación". ALESSANDRI et al. (2005) p. 520.

46 ALESSANDRI et al. (2005) p. 521.
} 


\section{EXTENSIÓN DEL FISCO EN LA ESTRUCTURA ADMINISTRATIVA CHILENA}

Teniendo claro que la noción de Fisco esta plenamente identificada con la actividad administrativa del Estado, surge la necesidad de determinar cuál es la extensión de este en la estructura administrativa del Estado chileno.

Tradicionalmente la doctrina, en concordancia con la jurisprudencia administrativa de la Contraloría General de la República ${ }^{48}$, explica el panorama estructural de la Administración del Estado desde el punto de vista subjetivo que hemos venido tratando. Vale decir, atendiendo a la personalidad jurídica del Estado y sus distintos organismos e instituciones, esto nos lleva de manera natural a sostener que el cuadro administrativo chileno gira en torno a los conceptos de centralización y descentralización administrativa ${ }^{49}$.

Dentro de esta línea sostiene el profesor Soto Kloss que resulta claro que el Estado de Chile actúa a través de personas jurídicas en lo que se refiere a la actividad administrativa estatal y que siguiendo la terminología que usa el constituyente, ellas serían: el Fisco, las municipalidades, y una serie de personas jurídicas administrativas con características bien definidas y que pueden incluirse en tres diversos tipos: instituciones semifiscales, empresas estatales, y organismos o entidades dotados de autonomía especial ${ }^{50}$.

Dentro de este esquema podemos distinguir dos órdenes administrativos: "una administración fiscal, que actúa bajo la personalidad jurídica 'fisco', y que está vinculada con el Presidente de la República por medio de una relación jerárquica: la configuran los

47 Como hemos visto, en el ámbito europeo la palabra "Fisco" se emplea en su sentido más genuino, para referir en un contexto histórico determinado, a la creación técnica que se utilizó como instrumento de sometimiento del gobernante al Derecho. Esta denominación pasó a nuestra realidad normativa y dogmática para referir al Estado mismo y de manera más precisa al Estado en cuanto administración. Como expresa Claro Solar (1927) p. 449, "el Estado, considerado como administración, está dotado, por lo tanto, de personalidad jurídica propia. Concretada al patrimonio, es decir al derecho a los bienes y a su administración, se usa para designar el Estado la expresión Fisco, reservando aquella para su carácter político internacional"; en el mismo sentido, AYLWIN y AZÓCAR (1996) p. 179, "Estado y Fisco son dos denominaciones que se le dan a una misma persona jurídica, que es siempre de derecho público"; también en SiLva Cimma (1995) p. 138, respondiendo a la pregunta “¿Es lo mismo Estado que Fisco?”, concluye que el Estado desde un punto de vista orgánico, es una persona pública y sujeto de derechos patrimoniales, caso en el que nuestro ordenamiento positivo pasa a llamarlo Fisco, sin embargo el autor es crítico de esta denominación por cuanto estima que resulta preferible reservar su utilización para referirse al fisco su sentido propio, el histórico, a la teoría del fisco. De manera que el término "Estado" cuadra mejor con el Derecho Público Moderno. Expresa que "Dejando en claro -como lo hemos hecho- que el Fisco y Estado son una misma y única persona jurídica de Derecho público, hablaremos del Fisco, por que no podemos desconocer su existencia en el Derecho Positivo chileno".

$48 \mathrm{Al}$ efecto señala el Dictamen No 64.792 de 29 de septiembre de 1970: "Los servicios públicos se encuadran dentro del sector fiscal o de administración central y del sector autónomo o de administración descentralizada, según la personalidad jurídica que los habilite para actuar y atendiendo a la naturaleza de sus recursos. Así, son servicios fiscales o de administración central los que actúan bajo la personalidad jurídica del Fisco, del Estado en sentido restringido. Son entes autónomos o de administración descentralizada, los servicios públicos que tienen personalidad jurídica distinta del Fisco y manejan su propio patrimonio, pudiendo distinguirse entre ellos, como especies, a las instituciones y a las empresas publicas".

49 Una breve explicación acerca de estos conceptos en SILVA BASCUÑÁN (2000) pp. 521-524; también en VIVANCO (2002) p. 264.

50 SOTO KLOSS (1986), p. 19. 
ministerios y los servicios dependientes de ellos, servicios y ministerios que carecen de patrimonio propio y son alimentados o sostenidos por el Presupuesto General de la Nación", y "una administración no fiscal, compuesta por numerosas personas jurídicas que, ya sean por la función que realizan y llevan a cabo (funcionalmente descentralizadas) o por el territorio en el cual actúan (territorialmente descentralizadas), están dotadas de autonomía de gestión, tanto normativa como financiera, contando, en consecuencia, con facultades que la ley les ha conferido para actuar con independencia en la realización de los fines propios que les han sido encomendados, pero vinculadas todas ellas, por medio del Ministerio afín con su actividad, al Presidente de la República, centro unificador de la organización administrativa a través de sus poderes jurídicos de supervigilancia" ${ }^{51}$.

Vemos entonces que el profesor Soto Kloss coincidiendo con la jurisprudencia administrativa, distingue una administración personificada que estaría compuesta por todos aquellos entes administrativos descentralizados sea funcional o territorialmente. $Y$ una administración no personificada integrada por los entes administrativos centralizados, siendo esta última categoría la que constituye el Fisco.

El profesor Silva Cimma concuerda con esta visión subjetiva de la Administración del Estado. Ello se aprecia de su clasificación de los distintos tipos de servicios públicos, en la que utiliza como uno de los criterios de distinción la personalidad jurídica. En este contexto ha distinguido entre servicios públicos que no disponen de una personalidad jurídica propia, que serían aquellos que se cobijan bajo el manto de la personalidad jurídica del Fisco, y aquellos servicios públicos que tiene una personalidad jurídica especial de Derecho Público ${ }^{52}$.

Sin perjuicio de que este ha sido el criterio tradicionalmente aceptado para describir y caracterizar la estructura administrativa del Estado chileno, hay autores que se muestran en desacuerdo con esta manera de acercarse al asunto.

El profesor Rolando Pantoja reconoce la realidad doctrinaria que ha tendido a explicar la estructura administrativa del Estado desde la perspectiva subjetiva, caracterizando a la Administración del Estado desde un punto de vista organizativo como un conjunto de personas jurídicas. Señala que para la ciencia del derecho la personalidad jurídica representa una idea base de la construcción de esta estructura, circunstancia que explicaría que "[...] la personificación de los organismos administrativos ha demostrado ser el eje rector del cuadro de clasificación de la Administración Pública” 53.

\footnotetext{
51 Soto Kloss (1986) p. 22.

52 "Pueden distinguirse unos servicios públicos de otros, recurriendo al elemento personalidad jurídica. A menudo los servicios públicos no disponen de una personalidad jurídica propia, por la sencilla razón de que no han menester de ella, ya que no gozan de recursos o bienes propios que administrar e invertir. En tal caso, se cobijan bajo el manto de la personalidad jurídica del Fisco, por intermedio de la cual actúan patrimonialmente. La mayor parte de los servicios dependientes de la Administración Central invisten ese carácter. Sin embargo, hay también servicios de la Administración del Estado que, por disponer de un patrimonio propio de bienes públicos, o de bienes fiscales que han sido afectados específicamente para formar ese patrimonio, requieren de una personalidad jurídica especial de Derecho Público, distinta del Fisco, para poder administrar ese patrimonio. El elemento personalidad jurídica constituye pues un factor de diferenciación entre los diferentes servicios de la Administración chilena”. SiLva Cimma (1995) p. 120.

53 PANTOJA (1998) p. 159.
} 
Sin embargo, este autor se muestra crítico de esta visión señalando que esta perspectiva tuvo sustento normativo solo hasta que entró a regir la Constitución de $1980^{54}$. Al cambiar la nueva norma constitucional el paradigma fiscalista por el de servicialidad del Estado, habría dejado obsoletas aquellas caracterizaciones de la Administración estatal basadas en criterios de "organicidad". Expresa que esta explicación caracteriza como servicio público a todos los entes con alguna vinculación estatal, criterio que no sería útil para describir el lugar que ocupan en la estructura administrativa del Estado, por ejemplo, las empresas públicas ${ }^{55}$.

Para el autor, una clasificación de la Administración del Estado necesita estructurarse a partir de los puntos de vista admitidos por la Constitución Política. Desde esta perspectiva, la Administración habría de articularse en seis grandes circuitos administrativos de común origen, sector público, y compartida finalidad, servicio a las personas y contribución al bien común. Ellos son: el constituido por el Estado persona-jurídica, integrado por los ministerios subsecretarías, las secretarías regionales ministeriales, las intendencias, gobernaciones y los servicios públicos fiscales, dependientes o de administración central; el formado por los servicios descentralizados; el que configuran los servicios constitucionalmente autónomos que nacen de la Constitución Política de la República; el constituido por los servicios legalmente autónomos generados por el legislador a través de diversas leyes de mayor o menor amplitud, que presentan como constante aceptada para todos ellos la de ser servicios descentralizados, pero a la cual se le adicionan tales características de acción y de regulación que emergen como tipos categorizables de una manera propia y original dentro del cuadro orgánico de la Administración pública [Superintendencias y Universidades estatales]; el circuito formado por las empresas del Estado; y finalmente, el constituido por los Fondos administrativos [sean de origen constitucional o legal ${ }^{56}$.

Nos parece que el esquema propuesto por el profesor Pantoja planteando una clasificación de la Administración Pública orientada desde el punto de vista de los nuevos principios administrativos establecidos por la Constitución Política de 1980, no es una perspectiva que excluya las caracterizaciones propuestas por el resto de la doctrina examinada.

En efecto, pensamos que esta proposición es conciliable con aquellas que describen el cuadro de la administración estatal desde la perspectiva subjetiva, ello considerando que esta visión también encuentra sustento en la Constitución Política ${ }^{57}$ además de

54 "Con todo, al diseñar a la administración como un conjunto de personas jurídicas, la concepción individualista no sistematizó la visión constitucional de la Administración pública; restringió su óptica al encuadrar simplemente los organismos administrativos en los conceptos de corporación y de fundación civiles, en un intento doctrinal por sustituir la teoría de los servicios públicos acuñada por el Estado social por la teoría de las personas jurídicas, de suyo conocida en el ámbito del derecho, esfuerzo que al carecer de base empírica y de demostración, puesto que solo fue afirmación, dejó oscilando en el ambiente administrativo la duda acerca de cuál era y es, realmente, la visión arquitectural de la Administración pública aceptada por el Código Político de 1980", PANTOJA (1998) p. 161.

55 PANTOJA (1998) pp. 204 y ss.

56 PANTOJA (1998) pp. 206 y 207.

57 Artículo $3^{\circ}$ inciso 20: "La administración del Estado será funcional y territorialmente descentralizada, o desconcentrada en su caso, de conformidad a la ley". 
constituir un criterio de clasificación eminentemente jurídico-técnico y, en nuestra opinión, desprovisto por tanto de consideraciones valóricas que pudieran oponerse a aquellas formuladas por el profesor Pantoja.

Nuestra afirmación se funda principalmente en que la articulación de la Administración en estos seis circuitos administrativos puede ser conciliada con las categorías que distinguen entre Administración fiscal y no fiscal o entre administración centralizada y descentralizada, dependiendo de la nomenclatura que decidamos escoger.

Esta conciliación se logra encuadrando estos seis circuitos dentro de alguna de las dos categorías sostenidas por la doctrina tradicional, este encuadramiento dependerá de si el ente en cuestión goza de personalidad jurídica propia o actúa bajo la personalidad jurídica del Fisco. Así por ejemplo, dentro de la categoría de Administración fiscal o centralizada podemos ubicar al primer grupo de circuitos administrativos, el del Estado persona-jurídica.

\section{CAPACIDAD DE LA ADMINISTRACIÓN DEL ESTADO PARA SER PARTE}

Teniendo en consideración los antecedentes expuestos se concluye que todos los entes e instituciones que integran la Administración del Estado actúan de una u otra manera personificados, y esta personificación ha tenido una importancia capital a la hora de determinar la extensión o alcance de la noción de Fisco. Desde este punto de vista debemos entender comprendida dentro de la idea de Fisco toda aquella actividad administrativa que no haya sido personificada, sea legal o constitucionalmente.

Ahora bien, la importancia de esta realidad para el tema que nos ocupa radicará en la determinación que hagamos de la influencia que tiene la personificación en la capacidad del Fisco tanto para ser parte en juicio como para actuar válidamente en él.

Desde esta perspectiva, las consideraciones expuestas tomadas en su conjunto nos debieran servir como fundamento suficiente para afirmar como principio general, la plena capacidad del Estado y de su Administración tanto para ser parte en juicio como para actuar plenamente en ellos. Esta conclusión no es más que una consecuencia natural de su carácter subjetivo.

Se debe considerar que la gran mayoría de los argumentos y fundamentaciones, sean históricas o doctrinarias, que se dan con relación a la existencia jurídica del Estado como una persona jurídica se han desarrollado vinculados a la idea del sometimiento de este al Derecho, como consecuencia de dicho sometimiento debe colegirse que el Estado en su conjunto y la Administración individualmente considerada (tanto fiscal como autónoma), están a su vez sometidas a la jurisdicción ya que esta es la única vía posible para que se cumpla con este objetivo y exista efectivamente Estado de Derecho.

Sin perjuicio de lo señalado, veremos a continuación cómo este principio general que entrega la capacidad para ser parte en virtud de la personalidad ha experimentado atenuaciones, principalmente en el campo del derecho privado, pero también respecto de entes de naturaleza pública. 


\section{CAPACIDAD PARA SER PARTE DE ENTES SIN PERSONALIDAD}

Según señalábamos, Savigny tuvo una importante influencia en nuestra codificación civil en materia de personas jurídicas. Para este autor, dentro de los varios tipos de personas morales existen algunas de existencia natural o necesaria tales como el Estado ${ }^{58}$.

No obstante lo anterior, estimamos que la personalidad jurídica, la técnica de la personificación, en lo que se refiere a personas morales constituye un recurso de carácter eminentemente formal ${ }^{59}$. En consecuencia, desde un punto de vista procesal existen múltiples realidades que escapan de su esfera de acción. Tal es el caso de los entes sin personalidad.

Estas realidades no personificadas necesitan igualmente de la capacidad para poder solicitar la tutela de sus derechos e intereses, como es necesaria asimismo su aptitud para ser demandados en juicio a fin de dar protección a quienes interactúan con ellas ${ }^{60}$.

Las formulaciones tradicionales de atribución de capacidad para ser parte en razón de la personalidad resultan insuficientes para satisfacer estas necesidades. En consideración a ello, desde hace ya bastante tiempo ${ }^{61}$ la doctrina ha agregado a estas hipótesis

58 Vid. supra nota 42; BALMACEDA (1943) p. 76, señala que para Savigny las personas jurídicas son seres ficticios, creaciones de la ley, pero que esta teoría [la teoría de la ficción] solo se aplica a las personas privadas. Existen personas que no son ficticias y que por el solo hecho de nacer se imponen al derecho. Entre estas, lógicamente, debe estar el Estado.

59 CORRAL (1990) p. 318, sostiene que con relación a las personas naturales una perspectiva realista impide negar importancia jurídica al concepto ontológico de persona, haciéndose evidente que los criterios del derecho en esta materia deben adecuarse a aquello que se nos presenta como persona de acuerdo a la naturaleza humana. En consecuencia, cuando se trata de personas físicas o naturales no sería acertado hablar de la personalidad como un instrumento normativo, ya que una concepción formalista, derivada explicita o implícitamente de un pensamiento positivista, conduce a la negación del concepto de persona; en contra ARIÑo (1970) p. 87, estima que se considera persona jurídica a aquel individuo, ente u organización a la que la ley se la conceda, sean cuales sean sus características. La condición de persona jurídica la confiere siempre el ordenamiento, el derecho objetivo, no solo a las personas morales, sino también a las físicas, ya que no siempre los seres humanos alcanzan la personalidad; no lo eran, por ejemplo, los esclavos en Roma.

60 Así lo ha declarado la Corte Suprema al hacer suyas las consideraciones esgrimidas por la Corte del Trabajo de Concepción en su informe emitido en el marco de un recurso de queja. En él se expresa, refiriéndose al demandado en los autos, que si bien la citada asociación no constituye persona jurídica, las labores que desarrolla, su reconocimiento por los asociados y por las autoridades públicas, el hecho de contar con nombre propio, patrimonio, órganos de representación y aun con domicilio, llevan a concluir que constituye una entidad que presenta todas las características de una persona jurídica, en sus diversas relaciones con sus dependientes y con terceros, a la que solo le falta su reconocimiento legal (Considerando No 12); y que la carencia de personalidad jurídica no la exime de su responsabilidad frente a los terceros que contratan con ella (contrato de trabajo), ya que al actuar públicamente en el campo del derecho en su calidad de asociación, no pudo menos que inducir a los terceros de buena fe a entender que ella estaba provista de dicha personalidad (Considerando No 13), Vejar Vera, Carlos y otros (Recurso de Queja) (1968). En este caso el fundamento que justifica la capacidad para ser parte es el "favorecimiento de la apariencia", cfr. ROMERO (2003) p. 315.

61 Ya CHIOVEnda reconocía y comentaba la existencia de estos casos en los que se reconocía capacidad para ser parte a entes sin personalidad. Cfr. CHIOvenda (1977) pp. 11 y ss. 
tradicionales a ciertos entes que pese a no tener formalmente personalidad jurídica, cuentan, sin embargo, con capacidad para ser parte.

Se trata aquí de ciertas entidades colectivas o masas de bienes respecto de las cuales el ordenamiento jurídico, por distintas razones ${ }^{62}$, reconoce la aptitud necesaria para tener la calidad de parte en juicio. Estas entidades son los que alguna doctrina ha denominado "casos intermedios", realidades que sobrepasan a la persona física pero no llegan a la existencia de una persona jurídica ${ }^{63}$.

En nuestro ordenamiento jurídico constitucional, la doctrina ha destacado el importante aporte que la acción de protección ha significado en esta materia, constituyéndose esta como una acción en la que es reconocida la capacidad para ser parte de entes no personificados 64 .

En el plano legal, un claro ejemplo de capacidad para ser parte otorgada a una entidad colectiva no personificada lo encontramos en la Ley No 19.537 de 1997. Al regular dicha ley el régimen de administración de los bienes comunes de las edificaciones acogidas a esta normativa establece tres órganos administradores: la Asamblea de Copropietarios; el Comité de Administración y el Administrador. De estas, solo la existencia del administrador es eventual, caso en el que las funciones y atribuciones que de acuerdo a la ley le corresponden son ejercidas por el presidente del comité de administración.

La ley no reconoce personalidad jurídica a ninguno de los órganos de administración que hemos señalado, como tampoco se la reconoce a la colectividad de copropietarios. Sin embargo, expresamente reconoce capacidad para ser parte a estos copropietarios colectivamente considerados. Explícitamente hace este reconocimiento en el art. 23 cuando atribuye al administrador del edificio o en su defecto al presidente del comité de administración la representación judicial activa y pasiva de los copropietarios, con las facultades del inciso primero del art. 7 del CPC, en las causas concernientes a la administración y conservación del condominio, sea que se promuevan con cualquiera de ellos

\footnotetext{
62 A este respecto expresa CORdón MOREno (1996b) p. 65, que existen determinados supuestos en los que, por razones prácticas o de justicia, es preciso reconocer capacidad para ser parte, capacidad para demandar o para ser demandados, a determinados entes no dotados formalmente de personalidad y que responden a realidades diferentes, pero que actúan en el tráfico jurídico. "Aplicar la regla de personalidad en estos casos supondría imponer la regla de que actuasen como demandantes o demandados todos los integrantes del ente (en cuyo caso habría que determinar su vinculación mancomunada o solidaria) y esta solución resulta, por complicada y por insegura para quienes mantienen relaciones con el ente en cuestión, totalmente insatisfactoria. El problema se ha planteado respecto de las comunidades de bienes, los patrimonios autónomos (por ejemplo la herencia yacente), las uniones temporales o permanentes sin personalidad, las sociedades irregulares, etc.

63 Se refiere a las uniones sin personalidad, sociedades irregulares, patrimonios autónomos (herencia yacente; masas activas del concurso y la quiebra) y grupos afectados (intereses difusos). MONTERO AROCA et al. (1991) p. 23.

${ }^{64}$ ARANCIBIA (1999) p. 9. La historia del establecimiento del recurso de protección da cuenta de esta realidad. Al interior de la comisión constituyente se dejo establecido que la acción podría ser interpuesta tanto por personas naturales como jurídicas y tanto de derecho privado como de derecho público, y también las personas morales, es decir, grupos de personas que carecen de personalidad jurídica. VERDUGO (1988) p. 39.
} 
o con terceros ${ }^{65}$. En consecuencia, ni la ley ni la jurisprudencia ${ }^{66}$ han tenido problema en aceptar la capacidad para ser parte de este ente colectivo.

Este sustrato eminentemente práctico es el que está presente en los demás casos en que se reconoce esta capacidad a entes no personificados. Así ha expresado Bujosa siguiendo a De la Oliva, que las identificaciones entre capacidad jurídica y capacidad para ser parte, y entre capacidad para obrar y capacidad procesal no son exactas, pues en realidad la capacidad en el proceso es más amplia que la capacidad civil. Probablemente está más ligada a valoraciones de conveniencia o necesidad, en el sentido de que aquello que en la realidad social revista cierta unidad se plantee también unitariamente en el proceso $^{67}$.

Atendida esta realidad doctrinaria y normativa ${ }^{68}$ que reconoce la capacidad para ser parte de entidades no personificadas ${ }^{69}$, cabe preguntarnos si es posible reconocer la misma capacidad a aquellos órganos del Estado que por pertenecer a la administración centralizada no tienen su propia personalidad jurídica y que actúan, por tanto, bajo la personalidad jurídica del Fisco. Vale decir, si es posible entender que los órganos de la administración no personificada, o al menos algunos de ellos, pueden directamente ocupar la posición de parte en el proceso.

65 Como hemos dicho, la norma no le reconoce personalidad jurídica, sin embargo, resulta evidente la necesidad que esta colectividad tiene de contar con la referida capacidad ya que, de lo contrario, los copropietarios del edificio se verían impedidos, por ejemplo, del necesario cobro judicial los gastos comunes. Como resulta también evidente la necesidad de poder demandar a este tipo de entidades. De ahí que la ley reconociera a los copropietarios la capacidad para ser parte.

${ }^{66}$ En la jurisprudencia no ha habido reparos en aceptar la calidad de parte de estas comunidades. En los autos sobre recurso de protección caratulados "González Estay con Comunidad Edificio Portal Alamos Torre A” seguidos ante la I. Corte de Apelaciones de Valparaíso, causa rol No 85 - 2005, la Corte rechazó por razones de fondo la acción interpuesta por don Aníbal González Estay en contra de la comunidad Edificio Portal Alamos Torre A por los trabajos de mantenimiento que se efectuaban en la fachada del edificio y que ocasionaban desprendimientos de porciones de concreto desde alturas considerables con el consiguiente riesgo para quienes pasaban por el lugar. González Estay, Aníbal con Comunidad Edificio Portal Alamos Torre A (2005).

${ }^{67}$ Bujosa (1995) p. 155.

68 Otro caso presente en nuestra legislación es el título III del libro IV del Código de Comercio, De las quiebras. Específicamente el art. 27 señala que corresponde al síndico la representación de los intereses generales de los acreedores tanto en juicio como fuera de él. En consecuencia el síndico es la persona procesalmente capaz que la ley ha dispuesto para asumir la representación judicial de los acreedores cuando requieran ir a juicio para defender sus intereses. A este respecto la doctrina ha señalado que la junta de acreedores es el órgano encargado de manifestar la voluntad del sujeto activo de la quiebra, de la colectividad de acreedores. De acuerdo a la ley, los acreedores tienen la facultad de disponer de los bienes de la quiebra y sus frutos hasta pagarse de sus créditos. Y esta facultad no se otorga propiamente a los acreedores, sino a esta "asociación legal, y procesal, necesaria", que constituye la colectividad de acreedores. PUGA (1989) p. 372; en contra, ROMÁN (2007) p. 196, niega expresamente la capacidad para ser parte de la junta de acreedores por cuanto carece de personalidad jurídica, en consecuencia no puede ser sujeto de derechos u obligaciones, y por ende no puede demandar ni ser demandado.

69 Para otros casos de atribución de capacidad para ser parte a entes sin personalidad en nuestro ordenamiento legal, vid. Romero (2003) pp. 299 y ss., en el que se examinan casos en materia laboral, previsional, tributaria, personas jurídicas extinguidas y patrimonios independientes, entre otros. 


\section{CAPACIDAD PARA SER PARTE DE LA ADMINISTRACIÓN NO PERSONIFICADA}

De acuerdo a lo hasta aquí apuntado, la capacidad para ser parte del Estado en general y de su administración en particular, se manifiesta de manera patente vinculada a la personificación de los distintos agentes que la integran. Por una parte, y como regla general, a través de la personalidad jurídica del Fisco, persona que comprende o engloba toda aquella actividad estatal que no haya sido personificada de manera específica y que viene a ocupar su posición de parte en el proceso. Y por otra, a través de las diversas personas jurídicas que se integran a la administración del Estado dentro de la denominada administración descentralizada o autónoma, la cual, precisamente por contar con el elemento de la personificación se entiende facultada para ocupar por sí misma la posición de parte ${ }^{70}$.

El esquema descrito ofrece una explicación aparentemente clara y completa acerca de la capacidad para ser parte de los diversos tipos de entes que integran la administración del Estado. Sin embargo, existen casos en nuestro ordenamiento jurídico en que se produce un quiebre de este cuadro. Se trata de situaciones que podríamos asimilar a la recién vista capacidad para ser parte de entes no personificados. Son supuestos en que nuestro ordenamiento, saltándose el dogma o principio de la personificación como criterio para atribuir esta capacidad, permite que órganos integrantes de la administración no personificada se avengan al proceso ocupando la posición de parte por sí mismos, esto es, sin necesidad de recurrir a la personalidad jurídica del Fisco, que es lo que en propiedad correspondería si lleváramos hasta sus últimas consecuencias el principio de la personificación.

En el ámbito de la acción de protección no ha habido reparos en reconocer la capacidad para ser parte de los entes públicos no personificados. Como apunta RomE$\mathrm{RO}^{71}$, la jurisprudencia en la acción constitucional de protección al no tener límite legal en esta materia, ha admitido la capacidad para ser parte de sujetos o entes que conforme a la visión clásica, por carecer de personalidad jurídica, no tendrían esta aptitud. Así se ha admitido como parte pasiva de la acción a organismos de la administración centralizada del Estado como la Contraloría General de la República. Por tanto, al menos en lo que respecta a la acción de protección, la capacidad para ser parte se extiende no solo a personas naturales y jurídica, sino también a todo ente, grupo, asociación, organización o movimiento, admitiéndose dentro de estas posibilidades a entes no personificados de la administración del Estado, entes que en estos casos dejan de ampararse en el Fisco para poder ser parte en el juicio.

\footnotetext{
${ }^{70}$ De acuerdo al art. 33 del D.F.L. No 1/19.653 de 2001 del Ministerio Secretaría General de la Presidencia (ley orgánica de bases generales de la administración del Estado), la representación judicial y extrajudicial de los servicios descentralizados corresponderá a los respectivos jefes superiores, en consecuencia, el ordenamiento jurídico entiende que estos tienen plena capacidad para ser parte en juicio, para ocupar autónomamente la posición de parte, de otra manera no sería posible explicar que la ley entienda que tienen también plena capacidad procesal, vale decir, la aptitud para obrar por sí mismos en el proceso, circunstancia que se desprende del hecho de que la norma citada señala de manera específica el órgano interno que cuenta con dicha capacidad para ejecutar los actos procesales en el juicio.

${ }^{71}$ Romero (2003) p. 305.
} 
Tenemos aquí que el ordenamiento jurídico, como una forma de ampliar el espectro de eficacia de esta acción constitucional, ha estimado conveniente desvincularla de los criterios tradicionales de atribución de capacidad para ser parte en razón de la personalidad jurídica. Desvinculación que opera de manera general, es decir, en todos los casos en que se ejerza una acción de protección y por tanto con independencia de la naturaleza del ente que en definitiva asuma la calidad de parte.

En consecuencia, se establece a propósito del recurso de protección una excepción general al principio de la personificación de los entes públicos para atribuirles la capacidad para ser parte en juicio. Sin perjuicio de ello, es posible también encontrar excepciones específicas a este principio. Se trata de situaciones en que la ley, refiriéndose de manera especial a un determinado órgano de la administración no personificada, entiende que este puede atribuirse directamente la condición o calidad de parte en el proceso.

En este sentido se ha declarado por parte de nuestros tribunales, que tratándose de un servicio público desconcentrado "[...] este puede actuar directamente en juicio, sin intervención del organismo denominado Consejo de Defensa del Estado, cuando lo estime conveniente, deduciendo las acciones civiles y criminales en contra de terceros, para perseguir las responsabilidades a que hubiere lugar"72.

A nuestro entender, esta hipótesis se presenta cuando el ordenamiento, a propósito de la regulación propia de un determinado órgano o ente centralizado, no personificado, establece en su organización interna un funcionario al que le confiere su representación judicial. Nos encontramos en este caso frente a un órgano que tiene además de la capacidad para ser parte, la capacidad procesal para actuar por sí mismo en el proceso.

En efecto, en determinados casos la ley entrega la representación judicial de los órganos de la administración centralizada a uno de sus funcionarios, normalmente a su jefe superior ${ }^{73}$. Representación que se mantiene en tanto no sea asumida la que por ley se confiere al Presidente del Consejo de Defensa del Estado en conformidad al art. 18 No 1 del D.F.L. No 1 de 1993 del Ministerio de Hacienda ${ }^{74}$.

72 Caja de Previsión de la Marina Mercante Nacional (Recurso de Queja) (1970).

${ }^{73}$ Ejemplo de ello es el caso del Director del Servicio de Impuestos Internos. Funcionario al que en conformidad con lo dispuesto en las letras d) y e) del art. $7^{\circ}$ del D.F.L. No 7 de 1980 del Ministerio de Hacienda, corresponde la representación del Fisco, cuando fuere necesario, en la aplicación y fiscalización de los impuestos a que se refiere el artículo $1^{\circ}$ de la misma ley, sin perjuicio de la representación que corresponde al Presidente del Consejo de Defensa del Estado conforme a la Ley Orgánica de dicho Servicio, y representar al Servicio de Impuestos Internos en todos los asuntos, incluidos los recursos judiciales en que la ley le asigne la calidad de parte, y los recursos extraordinarios que se interpongan en contra del mismo Servicio con motivo de actuaciones administrativas o jurisdiccionales.

${ }^{74}$ De acuerdo a esta norma corresponde al Presidente del Consejo "La representación judicial del Fisco en todos los procesos y asuntos que se ventilan ante los tribunales, cualquiera sea su naturaleza, salvo que la ley haya otorgado esa representación a otro funcionario [...]". Asimismo, de acuerdo a lo establecido por el artículo 24 № 1 DFL No 1 de 1993 del Ministerio de Hacienda, los abogados procuradores fiscales dentro de sus respectivos territorios tiene la facultad de "representar judicialmente al Fisco con las mismas atribuciones del Presidente [...]". Si la ley atribuye en un determinado funcionario la representación judicial de un órgano o servicio será dicho funcionario quien ostentará tal representación. Sin embargo, en estos casos la norma deja a salvo la representación judicial del Presidente del Consejo de Defensa del Estado para que este la asuma por sí o por medio de apoderados "cuando lo estime conveniente" "cesando entonces la que corresponda a aquel funcionario". 
De esta manera, si el ordenamiento jurídico establece la posibilidad de que el jefe superior del respectivo ente u órgano asuma su representación judicial, entendemos que dicho reconocimiento lleva implícita la aptitud o capacidad del órgano en cuestión para ocupar la posición de parte por sí mismo, sin necesidad de recurrir a la personalidad jurídica del Fisco. Desde un punto de vista práctico, no hay necesidad de recurrir a ella sino hasta que tenga lugar la ejecución de una eventual sentencia, en cuyo caso lo que en realidad interesa es recurrir al patrimonio fiscal, y no propiamente a su personalidad jurídica.

Si la ley entrega por regla general la representación judicial del Fisco al Presidente del Consejo de Defensa del Estado, no tiene sentido que se la entregue también al jefe superior de un determinado órgano o servicio si dicha entrega no va acompañada también de la capacidad para ser parte de este, para ocupar por sí mismo la posición de parte. Esto es, sin recurrir a una personalidad que desde un punto de vista procesal le es innecesaria y que solo le sirve desde una perspectiva patrimonial. Se debe considerar que, como hemos visto, en la actualidad el ordenamiento jurídico no entiende la personificación como un requisito indispensable para ocupar la posición de parte en el proceso, ni en el ámbito privado ni el público. Por estas razones, no es extraño encontrar en la jurisprudencia de nuestros tribunales casos en que se ha admitido a un órgano de la administración no personificada ocupando la posición de parte. Manteniéndonos en el caso que hemos empleado preferentemente, el Servicio de Impuestos Internos es claro ejemplo de lo señalado, órgano al que no se le ofrece reparos para ser parte en los procesos vinculados a sus funciones y actuaciones ${ }^{75}$.

De especial interés con relación a este punto resulta la consideración de lo dispuesto en el numero 13) del artículo segundo del proyecto de ley que fortalece y perfecciona la jurisdicción tributaria (boletín No 3139-05, el que fue remitido con fecha 30 de septiembre de 2008 mediante oficio No 7709 de la Cámara de Diputados al Tribunal Constitucional para su control de constitucionalidad, y que fuera resuelto mediante sentencia de fecha 30 de diciembre de $2008^{76}$ y promulgado con fecha 13 de enero de 2009), que incorpora al Código Tributario el art. 117 cuyo inciso primero señala que "la representación del Fisco en los procesos jurisdiccionales seguidos en conformidad a los Títulos II, III y IV de este Libro [libro tercero, de los tribunales, de los procedimientos y de la prescripción], corresponderá exclusivamente al Servicio [de Impuestos Internos], que, para todos los efectos legales, tendrá la calidad de parte. Si este lo considera necesario podrá requerir la intervención del Consejo de Defensa del Estado ante los tribunales superiores de justicia”.

\footnotetext{
75 Como ejemplos de procesos en los que se ha admitido al Servicio de Impuestos Internos como parte, se pueden mencionar, Molina y Morel Inmob. y Const. S.A. con Servicio de Impuestos Internos (2006); Madariaga Bravo, Sergio Andrés con Servicio de Impuestos Internos (2006); Iduexport S.A. con Servicio de Impuestos Internos (2006); Lama Oviedo, Rodolfo Ignacio con Servicio de Impuestos Internos (2005).

76 De acuerdo a lo dispuesto en el considerando sexto de la sentencia de 30 de diciembre de 2008 del Tribunal Constitucional (Rol No 1243-08), la norma en comento fue excluida del análisis de constitucionalidad por no ser estimada como materia de la ley orgánica constitucional a la que alude el art. 77 de la Constitución.
} 
En este caso, nos parece que de manera inadvertida, la norma proyectada hace una asimilación entre la parte procesal y su representante judicial, ello por cuanto si se considera que desde el punto de vista organizativo el Servicio de Impuestos Internos (servicio público no personificado) y el Fisco son una misma persona jurídica, necesario es concluir que de acuerdo a la norma en comento, representante y representado son una misma persona. Dicho de otra forma, el sujeto que en conformidad a este proyecto de ley tiene la representación judicial del Fisco, el Servicio de Impuestos Internos, es en realidad la parte misma en el juicio y no su representante.

A similar conclusión ha llegado alguna doctrina refiriéndose al ordenamiento jurídico español, la que tomando como base una concepción organicista de la actuación de las personas jurídicas ${ }^{77}$ y considerando además el carácter unitario de la personalidad jurídica del Estado, ha estimado que el problema de la actuación de este en el proceso no dice relación con un problema de capacidad, sino que con una cuestión de competencia del órgano administrativo facultado para actuar en juicio a nombre del Estado. En este entendido, sostiene esta doctrina que "[...] el órgano que actúa en juicio [...] y la parte en cuyo nombre aquel actúa -el Estado- son un mismo sujeto. De este modo, no se trata tanto de ver en dicho órgano al 'defensor' de la parte, como a la propia parte en juicio"78.

Estimamos acertadas las conclusiones de esta doctrina en el entendido de que ellas descansan en el supuesto fundamental de que el órgano competente (facultado) para actuar en el proceso a nombre del Estado participa de la personalidad jurídica de este, y más concretamente de la personalidad de la Administración ${ }^{79}$. Sin embargo, este supues-

77 La teoría orgánica explica la actuación de las personas jurídicas apuntando su plena capacidad de obrar, lo que se traduce en una plena capacidad procesal. Aquí las personas jurídicas son sujetos con aptitud para manifestar su propia voluntad, lo que se logra entendiendo que los órganos legales o estatutarios establecidos para formar y exteriorizar la voluntad de la persona moral son parte integrante de ella. Una explicación acerca de la teoría del órgano, en LYON (1993) pp. 229-230; también en SANZ (1995) pp. 193 y ss.; GutiéRrez DE CABIEDES (1974) p. 269, apunta a la doctrina iuspublicista como el origen de esta posición. Señala que esta doctrina se adelantó a la iusprivatista en rechazar el concepto de representación como explicación del fenómeno de la actuación de las personas jurídicas y en trazar un tipo de subjetividad más exacto para calificarlo, que es el órgano. Apunta que según esta doctrina el órgano es una simbiosis de tarea y persona. La tarea es lo permanente del órgano y la persona es lo mudable. El órgano por naturaleza no es algo distinto del todo, como ocurre en el binomio representante representado, sino una parte de ese todo. Si se aplican estas elementales ideas del derecho público a la sociedad, la tarea o función procesal del órgano es servir de cauce a la actuación de la sociedad, no sustituirla o representarla.

78 JUAN SÁNCHEZ (1998) p. 139. De esta manera, "la identificación entre órgano que actúa y la parte procesal hace que la actuación en juicio del Estado deba ser estudiada, de nuevo, desde la óptica de las normas organizativas y de atribución de funciones en el seno del propio Estado". Así, los defectos en la actuación del Estado en juicio no se plantean en términos de incapacidad sino de incompetencia. "La estructuración de la administración estatal en múltiples órganos, con un cometido específico para cada uno, no es obstáculo para que todos ellos tengan reconocida plena capacidad de actuar limitada a su ámbito competencial. La trasgresión de las atribuciones propias de un órgano en concreto por otro órgano constituye no un defecto de capacidad de obrar, sino una infracción de las normas internas de reparto de competencias entre órganos administrativos” JUAN SÁNCHEZ (1998) p. 140.

${ }^{79}$ En el ordenamiento jurídico español, la Abogacía General del Estado-Dirección del Servicio Jurídico del Estado es un servicio con rango de subsecretaría, dependiente de la secretaría de Estado de Justicia del Ministerio de Justicia, y que por tanto no ostenta la calidad de ente personificado participando en consecuencia de la personalidad jurídica del Estado (Administración). Ello resulta de considerar lo dispuesto por 
to no tiene un sustento normativo general en nuestro ámbito jurídico si consideramos el carácter de órgano descentralizado, y por tanto personificado, del ente que en conformidad a la ley, y por regla general, tiene la competencia para actuar en el juicio a nombre del Estado, el Consejo de Defensa del Estado (art. 1, inciso 10 D.F.L. No 1 de 1993 del Ministerio de Hacienda) ${ }^{80}$. Bajo esta premisa no es posible identificar la actuación de este órgano con la actuación del propio Estado, ello por cuanto nos encontramos ante distintas personas jurídicas y no frente a un órgano del propio Estado que actúa dentro de sus competencias amparado en la personalidad jurídica del Fisco. Pero en el caso del proyectado nuevo art. 117 del Código Tributario no aparece esta distinción personal entre el Fisco y el órgano llamado a asumir su representación judicial y en consecuencia pensamos que es correcto afirmar que en este caso se produce confusión entre ambos, vale decir, que en realidad la parte es el Servicio de Impuestos Internos, conclusión que se ve sustentada por el tenor literal de la disposición y además por el número 36) del artículo segundo del proyecto de ley que fortalece y perfecciona la jurisdicción tributaria, que proyecta modificar el art. 145 del Código Tributario reemplazando en su inciso primero la palabra "Fisco" por "Servicio", con lo que la disposición quedará del siguiente tenor, "El reclamante o el Servicio podrán interponer los recursos de casación en contra de los fallos de segunda instancia" (la cursiva es nuestra).

Al margen de su capacidad como parte de la acción de protección, el caso de la Contraloría General de la República también resulta de gran interés como manifestación de un órgano no personificado con capacidad para ser parte. Para ello se debe considerar que su propia ley orgánica le reconoce esta capacidad en determinados juicios relativos a sus funciones.

Concretamente, el art. 128 del Decreto No 2421 de 1964 del Ministerio de Hacienda establece en su inciso $1^{\circ}$ que "En los juicios que se sigan ante los Tribunales Ordinarios de Justicia para perseguir el cumplimiento de la sentencia dictada en el juicio de cuentas, la acción será ejercitada por la Fiscalía, salvo que el Contralor General

los artículos 2 y 3 del Real Decreto 1125/2008, de 4 de julio, por el que se desarrolla la estructura orgánica básica del Ministerio de Justicia y se modifica el Real Decreto 438/2008, de 14 de abril, por el que se aprueba la estructura orgánica básica de los departamentos ministeriales, los que señalan en lo pertinente que la Secretaría de Estado de Justicia es el órgano superior del departamento al que corresponde, bajo la superior autoridad del Ministro, la dirección, impulso y gestión de las atribuciones ministeriales relativas a la superior dirección de la asistencia jurídica contenciosa y consultiva del Estado. De la Secretaría de Estado de Justicia dependen los siguientes órganos directivos: a) La Abogacía General del EstadoDirección del Servicio Jurídico del Estado (art. 2). La Abogacía General del Estado-Dirección del Servicio Jurídico del Estado, con nivel orgánico de subsecretaría, es el órgano directivo de los servicios de asistencia jurídica al Estado y otras instituciones públicas, con las competencias y funciones contempladas en la Ley 52/1997, de 27 de noviembre, de Asistencia Jurídica al Estado e Instituciones Públicas, y en el Reglamento del Servicio Jurídico del Estado, aprobado por el Real Decreto 997/2003, de 25 de julio (art. 3); en este sentido, PEDRAZ (1993) pp. 124-125, “Las abogacías del Estado, como las asesorías jurídicas de las CCAA [Comunidades Autónomas] carecen de personalidad jurídica propia y evidentemente no son organismos autónomos dotados de personalidad jurídica independiente [...]”.

80 "Art. $1^{\circ}$.- El Consejo de Defensa del Estado es un servicio público descentralizado, dotado de personalidad jurídica, bajo la supervigilancia directa del Presidente de la República e independiente de los diversos Ministerios". 
estime conveniente disponer otra cosa y sin perjuicio de las facultades que correspondan al Consejo de Defensa del Estado".

Nos parece que al disponer la ley que el ejercicio de la acción corresponde a la Fiscalía, ello debe entenderse como una facultad que se ejerce a nombre del órgano al cual está integrada esta repartición, de la Contraloría. Pero aun cuando no se entendiera de esta forma, igualmente estaríamos frente a un reconocimiento de capacidad para ser parte a un ente público no personificado, en este caso, de la Fiscalía de la Contraloría General de la República.

Más claro que el anterior es el caso del art. 85 inciso final del Decreto No 2.421 de 1964 del Ministerio de Hacienda. Esta norma prescribe que "[...] la fiscalización de la inversión de los fondos fiscales que perciban personas o instituciones de carácter privado, por leyes permanentes, a título de subvención o aporte del Estado, para una finalidad específica y determinada, se limitará a establecer si se ha dado cumplimiento a dicha finalidad. En caso de que se produzcan reparos sobre la materia, las acciones que procedieren serán entabladas ante la justicia ordinaria directamente por la Contraloría General o por el Consejo de Defensa del Estado [...]" (la cursiva es nuestra).

En este caso se facultad expresamente a la Contraloría para ejercer a nombre propio una acción judicial en las hipótesis señaladas. Facultad que pensamos solo puede ser entendida como un reconocimiento de capacidad para ser parte a este órgano autónomo de la administración no personificada. Con respecto a este tema resulta interesante considerar la categoría procesal de "capacidad relativa para ser parte" que algunos autores proponen y que consiste en que a ciertos entes se les reconoce capacidad para efectos de figurar como parte en juicio pero solo en relación a cierto tipo de acciones o para ocupar solo una posición dentro de la relación procesal. ${ }^{81}$ Este podría ser el caso de la Contraloría General de la República, ente que de acuerdo a la norma citada podría litigar autónomamente en los casos que la ley le concede esta posibilidad, debiendo en los demás casos hacerlo a través del Fisco.

A modo de resumen, si bien tradicionalmente la capacidad para ser parte en juicio se ha asociado con la personalidad jurídica, vemos cómo el ordenamiento se ha venido desentendiendo de esta regla o principio. Actualmente es posible encontrar no pocos casos en que la normativa confiere la calidad de parte procesal a entidades que no cumplen con el tradicional requisito de la personalidad. Encontramos ejemplos de ello en el ámbito del derecho privado, pero hemos visto cómo también ocurre que el derecho omite o prescinde de la personalidad respecto de entes de naturaleza pública, en algunos casos de manera general como en la acción de protección, y en otros de manera específica como en los casos de la Contraloría General de la República y del Servicio de Impuestos Internos.

Pero la capacidad para ser parte es solo la primera manifestación del presupuesto procesal de la capacidad. Como se dijo, está nos sirve para determinar si un sujeto o ente, se encuentre o no personificado, está facultado de manera abstracta para ocupar la posición de parte procesal, ello con independencia de que dicha capacidad nunca llegue a ser ejercida, con independencia de que nunca se llegue efectivamente a litigar.

Además de lo anterior, a la hora de concretar esta aptitud para ser parte es necesario contar con un presupuesto adicional, con la aptitud para ejecutar actos válidos en el proceso, esto es, con capacidad procesal. 


\section{LA CAPACIDAD PROCESAL}

Afirma Chiovenda ${ }^{82}$ que "Del mismo modo que se puede ser sujeto de derechos y no tener el ejercicio de los derechos, o tenerlo limitado, así también puede tenerse la capacidad para ser parte en juicio, y no el ejercicio de los derechos procesales. La capacidad para comparecer en juicio, o sea para realizar actos procesales con efectos jurídicos en nombre, o representando a otro, llámase capacidad procesal [...]"83.

Tal como ocurría con la capacidad para ser parte en relación con la capacidad jurídica o de goce, respecto a la capacidad procesal la doctrina la ha relacionado o vinculado con la capacidad de obrar o capacidad de ejercicio del derecho civil ${ }^{84}$.

Considerando lo anterior, el fundamento que la doctrina da para explicar la necesidad de esta categoría dice relación con los mismos motivos que justifican la necesidad de establecer causales de incapacidad de obrar o de ejercicio en el derecho material. Esto es, el aseguramiento por parte del ordenamiento jurídico de un estándar o nivel mínimo de madurez o aptitud para comprender y por tanto responsabilizarse de las consecuencias de los propios actos ${ }^{85}$.

Sin embargo, es preciso hacer notar que este fundamento se refiere a la capacidad de las personas naturales, y no resulta apto para explicar la capacidad procesal de las personas jurídicas.

En efecto, la doctrina apunta que los problemas relativos a la capacidad procesal se presentan solo con relación a las personas naturales ya que las personas jurídicas la tienen atribuida por su propia naturaleza ${ }^{86}$. Como afirman Montero Aroca, Ortells

\footnotetext{
${ }^{81}$ CORdón Moreno (1996b) p. 64.
}

82 Chiovenda (1977) p. 16.

83 Para PRIETO-CASTRO (1982) p. 278, la capacidad procesal, que también llama capacidad de obrar procesal, es la de ser sujeto activo en el proceso. La de estar o comparecer en juicio. " [...] Es la que se reconoce a los sujetos con capacidad de obrar civil, como aptitud para comprender la trascendencia de los actos procesales y hacerse cargo de sus consecuencias, como también para realizarlos válidamente cuando no deba intervenir otra persona como postulante".

${ }^{84}$ La capacidad procesal es la capacidad para comparecer como parte válidamente en juicio, "Coincide, es el reflejo procesal, de la 'capacidad de obrar' en materia civil; la de ejercitar derechos (no de poseerlos, pero sin poder ejercerlos: eso es la capacidad jurídica o para ser parte) y asumir obligaciones”, FAIRÉN (1990) p. 286.

85 Como apunta CARnelutTi (1944) p. 25, "Si ante el juez o ante el oficial ejecutivo se presentan a pedirle una sentencia o un proveimiento de ejecución un niño o un loco, todo el mundo diría que ni el juez ni el oficio ejecutivo deben proveer. Esta opinión general responde al principio de que para actuar en juicio hacen falta ciertas cualidades de edad y de salud mental, sin que sea preciso explicar las razones de tal principio"; en la misma línea, "[...] Parece lógico y razonable que las mismas razones que impiden a un sujeto jurídico vender o donar, por sí mismo, válidamente, lo que es suyo, impidan que pueda, por sí mismo, realizar actos procesales válidos, comenzando por demandar o por acudir al proceso -también por sí mismo- en calidad de demandado”, De la Oliva y FernándeZ (1992) p. 435.

${ }^{86}$ En contra de esta posición otro sector de la doctrina ve en las personas jurídicas una hipótesis más de incapacidad que se agrega a las tradicionales que afectan a las personas naturales. Para estos autores las personas jurídicas deben ser consideradas como sujetos incapaces de ejercicio y como consecuencia de ello también desde un punto de vista procesal. En este sentido GOLDSCHMIDT (1936) p. 229, sostiene que una parte es procesalmente capaz cuando puede obligarse por contrato, o en otras palabras, cuando posee capacidad de obrar. Por consiguiente, carecen de capacidad procesal las personas jurídicas y las asociaciones de personas con capacidad para ser partes, así como las masas de bienes y los niños menores de 7 años; en 
Ramos y Gómez Colomer, en el derecho jurisdiccional no todos los que tienen capacidad para ser parte tiene capacidad procesal. Pero debe advertirse que los problemas relacionados con esta capacidad no se refieren a las personas jurídicas, sino a las físicas. Respecto de las primeras se debe examinar quién actúa por ellas, pero desde su constitución tienen capacidad de obrar ${ }^{87}$.

Puelma Accorsi ${ }^{88}$ señala que en nuestro país no existen normas generales que limiten la capacidad de actuación de las personas jurídicas en el ámbito patrimonial. Las normas se refieren al ámbito de las atribuciones de sus representantes. Ello es importante porque un acto de una sociedad nunca será nulo o ineficaz por falta de capacidad, sino que podrá serlo por estar prohibido o faltarle requisitos legales o ser inoponible a la sociedad por falta de personería de sus presuntos representantes. Se concluye entonces, que las personas jurídicas solo tienen limitantes de capacidad emanadas de su naturaleza ideal, no corporal. Por consiguiente son incapaces, por ejemplo, de ejecutar actos del derecho de familia u otros actos reservados por su naturaleza a personas naturales ${ }^{89}$.

la misma línea DíEZ-PICAZO (1979) p. 70, afirma que la persona jurídica debe ser estimada como un ser incapaz de obrar por sí mismo que, a semejanza de lo que ocurre con los demás incapaces, necesita valerse de un representante legal. El fundamento de esta incapacidad vendría dado por la imposibilidad de estos entes para actuar por sí mismos. CARNELUTTI (1944) p. 32, lo explica afirmando que el substrato de las personas jurídicas está constituido invariablemente por un grupo de interesados que es inidonio para la acción, no por las condiciones de los hombres que lo forman, sino por su número. En consecuencia, no cabe pensar en que el contrato o el proceso relativos a los intereses de una sociedad anónima o de un municipio, se celebren o conduzcan mediante la acción de todos los socios o todos los vecinos. Por tanto, en este caso, al igual que en el de los incapaces, el ejercicio se atribuye también a uno o más administradores (representantes), que tienen un oficio y una figura por completo análogas al del progenitor o del tutor; En nuestra opinión, la inclusión de las personas jurídicas dentro de la categoría de los incapaces (tanto de ejercicio como procesales) obedece a una asimilación que tiene como único punto de apoyo el hecho de que en ambas situaciones (incapacidad de una persona natural y actuación normal de una persona jurídica) es requerida la actuación de un representante. En este sentido se ha pronunciado también alguna jurisprudencia al sostener "que lo normal y frecuente en la vida jurídica es que las personas incapaces y las jurídicas que tienen la intención de ejecutar un acto o celebrar un contrato, concurran a su otorgamiento y exterioricen su voluntad mediante un representante, que actúe a nombre de ellas, este principio lo incorpora el artículo 1448 del Código Civil que expresa [...]”. Instituto Siervas de Jesús con Corporación Educacional Kingstone Collage (1984).

87 Montero Aroca et al. (1991) p. 18. En el mismo sentido afirma Cordón Moreno (1996b) p. 66. Los problemas de capacidad se plantean básicamente en el ámbito de las personas naturales, ya que las personas jurídicas la tienen atribuida ex lege, aunque por definición han de comparecer y actuar en juicio por medio de sus representantes; también en DE LA Oliva y FerNÁndeZ (1992) p. 435. A la inversa de lo que ocurre con la capacidad para ser parte, los problemas de capacidad procesal se presentan en relación con las personas físicas, ya que a la personas jurídicas esta les viene reconocida per se, por su esencia.

88 Puelma (1998) p. 165.

${ }^{89}$ Pudiera replicarse que si las personas jurídicas tienen limitantes de actuación dadas por su naturaleza ideal, ello importaría que desde ese punto de vista deben ser consideradas como incapaces. A nuestro juicio desde una perspectiva procesal ello no puede ser visto de esa manera. Es indiscutible que la naturaleza propia de las personas jurídicas la imposibilita para ejecutar ciertos actos reservados solo para personas naturales, sin embargo, desde el ángulo procesal esto no constituye una hipótesis de incapacidad procesal sino que se trata de una incapacidad para ser parte, así por ejemplo, las personas jurídicas por su propia naturaleza son incapaces de ser parte en juicios relativos al derecho de familia como lo son una demanda de divorcio o de alimentos. En este sentido se debe recurrir al concepto ya visto de capacidad relativa para ser parte, vid. supra nota 81. 
Esta es la posición que nos parece ha sido mayoritariamente recogida por la doctrina de nuestros tribunales, así se ha fallado por la Corte Suprema "que en nuestro ordenamiento legal las personas jurídicas son entes capaces de contraer obligaciones y de ejercer derechos, de acuerdo con lo dispuesto en el artículo 545 del Código Civil. Sin esta capacidad no podría concebirse su existencia". "Los derechos que son capaces de adquirir o ejercer por intermedio de sus representantes legales gozan de la misma protección jurídica que los que pueden adquirir o ejercer las personas naturales" ${ }^{\prime \prime}$. En este mismo sentido ha declarado la Corte Suprema que "[...] de acuerdo al art. 550 del mismo código [Código Civil] las referidas personas tienen voluntad, al igual que las naturales, con la sola diferencia de que en ellas la aptitud volitiva radica en sus órganos o reunión legal [...]"91.

El art. 8 del Código de Procedimiento Civil dispone que "el gerente o administrador de sociedades civiles o comerciales, o el presidente de las corporaciones o fundaciones con personalidad jurídica, se entenderán autorizados para litigar a nombre de ellas con las facultades que expresa el inciso $1^{\circ}$ del artículo anterior, no obstante cualquiera limitación establecida en los estatutos o actos constitutivos de la sociedad o corporación". Esta norma establece el órgano con capacidad procesal para actuar en juicio a nombre de estos tipos de personas jurídicas. A su turno, los arts. 40 y 49 de la Ley 18.046 de 1981 señalan cuáles han de ser los órganos que ejerzan la capacidad procesal en nombre de las Sociedades Anónimas, disponiendo a estos efectos que esta será ejercida por el Directorio y por el gerente de la sociedad.

Las normas apuntadas señalan el órgano con capacidad procesal para actuar en juicio a nombre de distintos tipos de personas jurídicas consagradas en nuestro ordenamiento. Como en estos casos, la ley regulando cada clase de persona jurídica señala cómo estas han de ejercer su capacidad procesal ${ }^{92}$, vale decir, cuál es el órgano interno a través del cual estas pueden ejecutar válidamente actos procesales tales como el ejercicio

90 Contra Félix Antonio Olivares Rosas (1982); también afirmando la plena capacidad de obrar de las personas jurídicas se ha fallado que el art. 1445 inciso $3^{\circ}$ del Código Civil establece que 'la capacidad legal de una persona consiste en poderse obligar por sí misma, y sin el ministerio ni autorización de otra', y el artículo siguiente (1446) agrega que 'toda persona es legalmente capaz, excepto aquellas que la ley declara incapaces, y luego el art. 1447 señala quiénes son absolutamente o relativamente incapaces o están afectos a incapacidades particulares o especiales $\left(4^{\circ}\right)$. "Que los sentenciadores al declarar que la Sociedad actora carece de capacidad para ejercer derechos sobre el predio demandado y -más concretamente- para obligarse válidamente a entregar talaje al dueño del predio y exigir de este el pago del precio convenido; y al resolverlo así, sin especificar si es absoluta, relativa o particular y aún omitiendo citar la disposición legal que la establezca -que por lo demás no existe- se apartaron de lo expuesto y vulneraron el artículo 1446 del Código Civil, dando por establecida una incapacidad no consagrada legalmente" (7o), Sociedad Agrícola de Reforma Agraria “Asentamiento Collipulli" con Mohr H. Rodolfo (1971).

${ }^{11}$ Letelier del Solar, Mariana y otro con Soc. de Inversiones Lyon Plaza S.A. (1999).

92 Como otros ejemplos se pueden citar el inciso $2^{\circ}$ del art. 424 del Código de Comercio que regula la Sociedad por acciones señalando que esta "tendrá un estatuto social en el cual se establecerán los derechos y obligaciones de los accionistas, el régimen de su administración y los demás pactos que, salvo por lo dispuesto en este Párrafo, podrán ser establecidos libremente. En silencio del estatuto social y de las disposiciones de este Párrafo, la sociedad se regirá supletoriamente y solo en aquello que no se contraponga con su naturaleza, por las normas aplicables a las sociedades anónimas cerradas”, en consecuencia respecto de este tipo societario la capacidad procesal se ejercerá en conformidad al régimen de administración establecido en su estatuto, o en silencio de este, en conformidad a las normas de las sociedades anónimas; 
de una acción judicial a través de la demanda, ser legalmente emplazada, y todos los demás actos procesales que una parte puede ejecutar durante el desarrollo del proceso.

Con relación a las personas jurídicas de derecho público se aplica el mismo principio recién visto. Vale decir, es la ley la que establece el órgano con capacidad procesal para ejecutar los actos procesales a nombre de la persona jurídica. O de modo más concreto, es la ley la que establece el órgano con capacidad procesal para actuar judicialmente a nombre del Fisco o del órgano de la administración descentralizada en su caso.

En efecto, tal como acontece en otros ordenamientos jurídicos ${ }^{93}$, en nuestro sistema la capacidad procesal del Estado se ejerce a través de funcionarios públicos especiales. Por regla general el Fisco como persona jurídica tiene establecido por ley como órgano con capacidad procesal al Presidente del Consejo de Defensa del Estado y al competente Abogado Procurador Fiscal ${ }^{94}$.

Sin perjuicio de lo anterior, la ley establece excepciones específicas a esta regla, ellas resultan de los casos en que se atribuye a un determinado funcionario la representación judicial de un órgano no personificado. En estos casos será dicho funcionario quien ostentará tal capacidad. Pero quedando a salvo la representación judicial del Presidente del Consejo de Defensa del Estado para que este la asuma por sí o por medio de apoderados cuando lo estime conveniente, cesando entonces la que corresponda a aquel funcionario (art. 18 No 1 D.F.L. No 1 de 1993 del Ministerio de Hacienda) ${ }^{95}$.

De esta manera, siguiendo con el ejemplo del Servicio de Impuestos Internos, tenemos que la representación judicial del Servicio será asumida por el Director Nacional hasta que eventualmente el Presidente del Consejo de Defensa del Estado estime conveniente asumirla por sí o por intermedio de apoderados, acto que haría cesar la que hasta ese momento ostentaba el referido Director.

En lo que se refiere a la capacidad procesal de los entes estatales personificados ${ }^{96}$ el sistema funciona de manera inversa al anterior, vale decir, adjudicando de forma

Del mismo modo, el art. 4 de la Ley No 3.918 de 1923 establece que el régimen de administración de la sociedad de responsabilidad limitada será el aplicable a las sociedades colectivas, con lo cual su capacidad procesal debe ser ejercida en conformidad al art. 8 del Código de Procedimiento Civil.

93 “[... la representación y defensa del Estado y de sus Organismos Autónomos, salvo que, en cuanto a estos, sus disposiciones autoricen otra cosa, así como la de los órganos constitucionales, corresponderá a los letrados integrados en los servicios jurídicos del Estado [...]" SANZ (1995) p. 198; también en GUASP y ARAGONESES (2002) p. 196, “[...] el Estado, sus organismos autónomos y los Organismos constitucionales serán representados y defendidos por los Abogados del Estado integrados en el Servicio Jurídico del Estado [...]"; FAIRÉN (1990) p. 287. "En cuanto al Derecho público, el Estado tiene como órgano con capacidad procesal, el Abogado del Estado [...]".

94 Vid. supra nota 74.

95 Esta facultad es conferida por la ley exclusivamente al Presidente del Consejo de Defensa del Estado, no existiendo la posibilidad de que ella sea ejercida por los abogados procuradores fiscales, imposibilidad que se desprende del No 1 del art. 24 D.F.L. No 1 de 1993 del Ministerio de Hacienda cuando expresa que la representación judicial del Fisco corresponde a estos funcionarios con las mismas atribuciones del Presidente, "[...] con excepción de la señalada en la parte final del no 1 del artículo 18 ".

${ }^{96}$ Encontramos en esta categoría, de acuerdo a lo prescrito en el número 2 del art. 18 D.F.L. No 1 de 1993 del Ministerio de Hacienda, a los gobiernos regionales, las municipalidades, las instituciones o servicios descentralizados y a las sociedades o corporaciones de derecho privado en que el Estado o sus instituciones tengan aporte o participación mayoritarios o igualitarios. 
excepcional la representación judicial del ente al Presidente del Consejo de Defensa del Estado. En efecto, tratándose de la administración descentralizada el D.F.L. No 1 de 1993 del Ministerio de Hacienda dispone que el órgano con capacidad procesal para ejecutar los actos de parte dentro del proceso será el Presidente del Consejo de Defensa del Estado solo en aquellos casos en que expresamente la ley lo autoriza (art. 18 No 2 en relación con los números 2 inciso $1^{\circ}, 3,4,5,7,8$ y 9 del artículo 3 D.F.L. No 1 de 1993 del Ministerio de Hacienda) y fuera de ellos la capacidad procesal del respectivo órgano será ejercida por el funcionario al que la propia ley se la atribuya.

Así por ejemplo, corresponderá al Presidente del Consejo de Defensa del Estado la representación judicial de los órganos descentralizados en los juicios que afecten bienes nacionales de uso público cuando la defensa de estos bienes no corresponda a otros organismos (art. 3 No 2 inciso 1 D.F.L. No 1 de 1993 del Ministerio de Hacienda). Aquí el ordenamiento no ha salvado la representación judicial del Presidente del Consejo de Defensa del Estado en caso de corresponderle esta a otros órganos o funcionarios. La redacción de la norma permite interpretar que la representación judicial del Presidente se encuentra condicionada a que no exista otra que se confiera a otros organismos. En consecuencia, a diferencia de lo que ocurre con la representación judicial del Fisco, si el ordenamiento ha entregado la representación del ente a otro órgano o funcionario ella excluirá la que pudiera corresponder al Presidente del Consejo de Defensa del Estado quedándole vedada la posibilidad de asumirla.

Es este el caso de los Gobiernos Regionales, entes de la administración descentralizada del Estado ${ }^{97}$ a los que en conformidad a lo dispuesto en el art. 24 letra l) del D.F.L. No 1 de 2005 del Ministerio del Interior les corresponde "Administrar, en los casos que determine la ley, los bienes nacionales de uso público", administración que es ejercida por intermedio del intendente en su calidad de órgano ejecutivo del Gobierno Regional y quien lo representa judicial y extrajudicialmente ${ }^{98}$. En consecuencia, en los juicios relativos a aquellos bienes nacionales de uso público que de acuerdo a la ley compete administrar al Gobierno Regional, la representación judicial del mismo corresponderá exclusiva y excluyentemente al Intendente por lo que será este quien ejercerá la capacidad procesal a nombre del órgano.

\section{CONCLUSIONES}

1. Si bien la capacidad para ser parte es una categoría procesal, esta no tiene una plena independencia respecto del concepto de capacidad jurídica o de goce.

\footnotetext{
${ }^{97}$ El inciso $2^{\circ}$ del artículo 13 del D.F.L. No 1 de 2005 del Ministerio del Interior, dispone que "Para el ejercicio de sus funciones los gobiernos regionales gozarán de personalidad jurídica de derecho público, tendrán patrimonio propio y estarán investidos de las atribuciones que esta ley les confiere”.

98 Art. 24 D.F.L. No 1 de 2005 del Ministerio del Interior, "Artículo 24.- Corresponderá al intendente, en su calidad de órgano ejecutivo del gobierno regional: h) Representar judicial y extrajudicialmente al gobierno regional, pudiendo ejecutar los actos y celebrar los contratos de su competencia o los que le encomiende el consejo"
} 
2. Las personas jurídicas tienen capacidad para ser parte desde que el ordenamiento las reconoce como tales. La capacidad para ser parte del Estado nació y se desarrolló en torno a su personificación.

3. Entre la doctrina nacional la idea de la personalidad jurídica del Estado ha sido un tema pacífico. La actitud mayoritaria apunta a dar por supuesta la personalidad jurídica única del Estado.

4. La doctrina y la jurisprudencia administrativa de la Contraloría General de la República, explican la estructura de la Administración del Estado desde un punto de vista subjetivo. Todos los entes e instituciones que integran la Administración del Estado actúan de una u otra manera personificados.

5. Desde un punto de vista procesal existen múltiples realidades que escapan del campo de acción de la personalidad. Tanto en el derecho privado como en el público la capacidad para ser parte no siempre depende del carácter subjetivo de la parte.

6. La ley establece en ciertos casos capacidad para ser parte de entes públicos no personificados, en ocasiones de modo general como en el caso del recurso de protección y en otras de manera específica, casos en que estos entes abandonan la personalidad jurídica del Fisco como presupuesto para ser admitidos como parte en juicio.

7. Los fundamentos que explican la necesidad del concepto de capacidad procesal se refieren a la capacidad de las personas naturales no resultando aptos para explicar la de las personas jurídicas.

8. La capacidad procesal de las personas jurídicas es entendida por la mayoría de la doctrina como una aptitud que estas poseen por su propia naturaleza, en consecuencia ellas no tiene problemas relacionados con su capacidad procesal.

9. Es la ley la que, regulando los distintos tipos de personas jurídicas señala los órganos de actuación de estas para los efectos de ejercer su capacidad procesal.

10. La capacidad procesal del Fisco se ejerce preferentemente a través del Presidente del Consejo de Defensa del Estado. En el caso de los entes públicos no personificados su capacidad es ejercida por el órgano o funcionario que señala la ley.

\section{BIBLIOGRAFÍA CITADA}

Alessandri RodrígueZ, Arturo, SOMARriva Undurraga, Manuel y VodAnOviC HakliCKA, Antonio (2005): Tratado de derecho Civil. Partes preliminar y general, (Santiago, Editorial Jurídica de Chile, 7a edición) v. 1, 657 pp.

Anabalón SAnderson, Carlos (1946): Tratado práctico de Derecho Procesal Civil chileno (Santiago, Ediciones de la Universidad de Chile) v. 2, 386 pp.

ARANCIBIA, MATTAR, Jaime (1999): "Capacidad procesal de los cuerpos intermedios que carecen de personalidad jurídica”, Gaceta Jurídica, No 233: pp. 7-21.

ARIÑO ORTIZ, Gaspar (1970): "La administración institucional: origen y personalidad", Revista de Administración Pública, No 63: pp. 85-130.

AYLWIN AZÓCAR, Patricio y AZÓCAR BRÜNnER, Eduardo (1996): Derecho Administrativo (Santiago, Universidad Nacional Andrés Bello) 384 pp.

Balmaceda LazCAno, Carlos (1943): El Estatuto de las personas juridicas (Santiago, Editorial Nascimento) 488 pp. 
BujOsa VADELL, Lorenzo (1995): La protección jurisdiccional de los intereses de grupo (Barcelona, José María Bosch Editor) 411 pp.

Calamandrei, Piero (1996): Instituciones de Derecho Procesal Civil (Traducc. Santiago Sentís Melendo, Buenos Aires, Librería El Foro) v. 2, 471 pp.

Carnelutti, Francesco (1944): Sistema de Derecho Procesal Civil. Composición del proceso (Traducc. Niceto Alcalá-Zamora y Castillo y Santiago Sentís Melendo, Buenos Aires, UTEHA Argentina) v. 2, 733 pp.

Chiovenda, José (1977): Principios de Derecho procesal Civil (Traducc. José CASAIS Y SANTALO, Madrid, Reus) v. 2, 924 pp.

Claro solar, Luis (1927): Explicaciones de Derecho Civil chileno y comparado (Santiago, Imprenta Cervantes) v. 5, 675 pp.

Cordón Moreno, Faustino (1996a): Proceso Civil de declaración (Pamplona, Aranzadi) $410 \mathrm{pp}$.

Cordón Moreno, Faustino (1996b): Apuntes de Derecho Procesal Civil (Pamplona, Facultad de Derecho Universidad de Navarra) 330 pp.

Corral Talciani, Hernán (1990): "El concepto jurídico de persona. Una propuesta de reconstrucción unitaria”, Revista Chilena de Derecho, vol. 17 No 2: pp. 301-321.

De la Oliva Santos, Andrés y Fernández, Miguel Ángel (1992): Derecho Procesal Civil (Madrid, Editorial Centro de Estudio Ramón Aceres, 3a edición) v. 1, 566 pp.

DíEZ-PICAZO, Luis (1979): La representación en el derecho privado (Madrid, Civitas) 322 pp.

FAIRÉN GUILlen, Víctor (1990): Doctrina general del Derecho Procesal. Hacia una teoría y ley procesal generales (Barcelona, Bosch) 604 pp.

García de EnTERría, Eduardo y FERnÁndeZ, Tomás (1993): Curso de Derecho Administrativo (Madrid, Civitas, 6a edición) v. 1, 802 pp.

GARCÍA DE ENTERrÍA, Eduardo (1992): "El concepto de personalidad jurídica en el Derecho Público”, Revista de Administración Pública, No 129: pp. 195-207.

GARRIDO FALla, Fernando (1982): "Reflexiones sobre un reconstrucción de los límites formales del Derecho Administrativo español”, Revista de Administración Pública, No 97: pp. 7-30.

Garrido Falla, Fernando (1994): Tratado de Derecho Administrativo (Madrid, Tecnos, $12^{a}$ edición) v. 1, 533 pp.

Goldschmidt, James (1936): Derecho Procesal Civil (traducc. Leonardo PRIETO-CASTRO, Barcelona, Editorial Labor) 916 pp.

GonzÁlez NaVArro, Francisco (1993a): Derecho Administrativo Español (Pamplona, Eunsa, 2a edición) v. 1, 1.242 pp.

GonzÁlez Navarro, Francisco (1993b): Derecho Administrativo Español (Pamplona, Eunsa, 2a edición) v. 2, 376 pp.

Guasp, Jaime y Aragoneses, Pedro (2002): Derecho Procesal civil. Introducción, parte general y proceso declarativos ordinarios (Madrid, Civitas, 5a edición) v. 1, 676 pp.

GUTIÉRREZ AlbORNOZ, Javier (1963): La concesión de personalidad jurídica a las corporaciones y fundaciones (Santiago, Editorial Jurídica de Chile) 158 pp.

Gutiérrez de Cabiedes, Eduardo (1974): Estudios de Derecho Procesal (Pamplona, Ediciones Universidad de Navarra) 529 pp. 
Hanisch Espíndola, Hugo (1980): "La influencia de Savigny en Bello en materia de personas jurídicas", Revista de Estudios Histórico-Jurídicos, tomo V: pp. 167-198.

JUAN SÁNCHEZ, Ricardo (1998): Las Comunidades Autónomas en el proceso civil (Granada, Comares) 492 pp.

Montero Aroca, Juan, Ortells Ramos, Manuel, Gómez Colomer, Juan Luis (1991): Derecho Jurisdiccional (Barcelona, Bosch) 2a edición, v. 2, 574 pp.

Montero Aroca, Juan (1994): La legitimación en el proceso Civil (Madrid, Civitas) $114 \mathrm{pp}$.

Navarro Hernán, Manuel (1998): Partes, legitimación y litisconsorcio en el proceso civil. Estudio jurisprudencial práctico (Madrid, Editorial Colex) 297 pp.

Lyon Puelma, Alberto (1993): Teoría de la Personalidad. Personas naturales, personas jurídicas (Santiago, Ediciones Universidad Católica de Chile) 343 pp.

Pantoja BauzÁ, Rolando (2007): El Derecho Administrativo. Concepto, características, sistematización, prospección (Santiago, Editorial Jurídica de Chile, 2a edición) 271 pp.

PANTOJA BAUZÁ, Rolando (1998): La organización administrativa del Estado (Santiago, Editorial Jurídica de Chile) 477 pp.

Pedraz Penalva, Ernesto (1993): Privilegios de las administraciones públicas en el proceso civil (Madrid, Civitas) $248 \mathrm{pp}$.

Prieto-Castro y Ferrándiz, Leonardo (1982): Tratado de Derecho Procesal Civil (Pamplona, Editorial Aranzadi) v. 1, 895 pp.

Puelma ACCORSI, Álvaro (1998): Sociedades (Santiago, Editorial Jurídica de Chile, 2a edición) v. 1, 403 pp.

PugA Vial, Juan Esteban (1989): Derecho concursal. El juicio de quiebras (Santiago, Editorial Jurídica de Chile) 505 pp.

Reyes Román, Gustavo y Soto Kloss, Eduardo (1980): Régimen jurídico de la Administración del Estado (Santiago, Editorial Jurídica de Chile) 124 pp.

ROMÁN ROdRÍGUEZ, Juan Pablo (2007): Instituciones de derecho concursal: efectos de la quiebra (Santiago, LexisNexis) 345 pp.

Romero Seguel, Alejandro (2006): Curso de Derecho Procesal Civil. La acción y la protección de los derechos (Santiago, Editorial Jurídica de Chile) v.1, 128 pp.

Romero Seguel, Alejandro (2003): "La capacidad de las personas jurídicas: una explicación procesal”, Cuadernos de extensión jurídica (Universidad de los Andes), No 7: pp. 293-318.

Santamaría Pastor, Juan Alfonso (2002): Principios de Derecho Administrativo (Madrid, Centro de Estudios Ramón Areces, 4a edición) v. 1, 738 pp.

SAMANES ARA, Carmen (2000): Las partes en el proceso civil (Madrid, La ley) 180 pp.

SANZ LlORENTE, Fernando (1995): La Representación procesal y el poder para pleitos (Granada, Comares) 302 pp.

SATTA, Salvatore (1971): Manual de Derecho Procesal Civil (Traducc. Santiago SENTís MELENDO y Fernando DE LA RÚA, Buenos Aires, Ediciones jurídicas Europa-América) v. 1, 303 pp.

Silva BASCuÑán, Alejandro (2000): Tratado de Derecho Constitucional (Santiago, Editorial Jurídica de Chile, 2a edición) v. 1, 588 pp. 
Silva Cimma, Enrique (1995): Derecho Administrativo chileno y comparado. El servicio público (Santiago, Editorial Jurídica de Chile) 323 pp.

Soto Kloss, Eduardo (1996a): Derecho Administrativo. Bases fundamentales (Santiago, Editorial Jurídica de Chile) v. 1, 359 pp.

Soto Kloss, Eduardo (1996b): Derecho Administrativo. Bases fundamentales (Santiago, Editorial Jurídica de Chile) v. 2, 480 pp.

SoTO Kloss, Eduardo (1986): "La organización de la administración del Estado: un complejo de personas jurídicas”, Gaceta Jurídica, No 73: pp. 16-23.

Toro Melo, David y Echeverría i Reyes, Aníbal (1902): Código de Procedimiento Civil anotado (Santiago, Imprenta Litografía i Encuadernación Barcelona) 874 pp.

Verdugo Johnston, Pamela (1988): El recurso de protección en la jurisprudencia (Santiago, Editorial Jurídica Ediar - Conosur Ltda.) 258 pp.

Vivanco MartíneZ, Ángela (2002): Curso de Derecho Constitucional. Bases conceptuales y doctrinarias del Derecho Constitucional (Santiago, Ediciones Universidad Católica de Chile) v. 1, 447 pp.

Vodanovic Haklicka, Antonio (2003): Manual de Derecho Civil. Parte preliminar y general (Santiago, LexisNexis, 4a edición) v. 1, 404 pp.

WaCH, Adolf (1977): Manual de Derecho Procesal Civil (traducc. Tomás A. BANZHAF, Buenos Aires, EJEA) v. 2, 537 pp.

\section{JURISPRUDENCIA CITADA}

Tribunal Constitucional, 30 de diciembre de 2008 (control de constitucionalidad del proyecto de ley que fortalece y perfecciona la jurisdicción tributaria, Rol 1243-08) disponible en: <www.tribunalconstitucional.cl> [fecha de consulta: 22 de enero de 2009].

Iduexport S.A. con Servicio de Impuestos Internos (2006): Corte de Apelaciones de Pedro Aguirre Cerda, 25 de mayo de 2006, en Revista de Derecho y Jurisprudencia, tomo 103, sección $2^{\mathrm{a}}$, p. 219.

Molina y Morel Inmob. y Const. S.A. con Servicio de Impuestos Internos (2006): Corte Suprema, 31 de mayo 2006, en Revista de Derecho y Jurisprudencia, tomo 103, sección $1^{\mathrm{a}}$, p. 154.

Madariaga Bravo, Sergio Andrés con Servicio de Impuestos Internos (2006): Corte Suprema, 22 de junio de 2006, en Revista de Derecho y Jurisprudencia, tomo 103, sección $1^{\text {a }}$, p. 197.

González Estay, Aníbal con Comunidad Edificio Portal Alamos Torre A (2005): Corte de Apelaciones de Valparaíso, 13 de abril de 2005, causa rol No 85 - 2005, disponible en: <http://www.poderjudicial.cl> [fecha de consulta: 22 de enero de 2009].

Lama Oviedo, Rodolfo Ignacio con Servicio de Impuestos Internos (2005): Corte Suprema, 20 de julio de 2005, en Revista de Derecho y Jurisprudencia, tomo 102, sección 1a, p. 624.

Letelier del Solar, Mariana y otro con Soc. de Inversiones Lyon Plaza S.A. (1999): Corte Suprema, 16 de noviembre de 1999, en Revista de Derecho y Jurisprudencia, tomo 96, sección $1^{\mathrm{a}}$, p. 192. 
Instituto Siervas de Jesús con Corporación Educacional Kingstone Collage (1984): Corte de Apelaciones de Concepción, 31 de julio de 1984, en Revista de Derecho y Jurisprudencia, tomo 81, sección 2a , p. 81.

Contra Félix Antonio Olivares Rosas (1982): Corte Suprema, 30 de agosto de 1982, en Revista de Derecho y Jurisprudencia, tomo 79, sección 4a , p. 188.

Sociedad Agrícola de Reforma Agraria "Asentamiento Collipulli" con Mohr H. Rodolfo (1971): Corte Suprema, 6 de septiembre de 1971, en Revista de Derecho y Jurisprudencia, tomo 68 , sección $1^{\text {a }}$, p. 259.

Caja de Previsión de la Marina Mercante Nacional (Recurso de Queja) (1970): Corte Suprema, 28 de abril de 1970, en Revista de Derecho y Jurisprudencia, tomo 67, sección $3^{\mathrm{a}}$, p. 31.

Vejar Vera, Carlos y otros (Recurso de Queja) (1968): Corte Suprema, 2 de julio de 1968, en Revista de Derecho y Jurisprudencia, tomo 65, sección 3a , p. 63.

\section{NORMAS CITADAS}

Ley No 3.918, sobre sociedades de responsabilidad limitada. Diario Oficial, 14 de marzo de 1923.

Ley No 18.046, sobre sociedades anónimas. Diario Oficial, 22 de octubre de 1981.

Ley No 19.537, Sobre copropiedad inmobiliaria. Diario Oficial, 16 de diciembre de 1997.

Ley No 19.886, Ley de bases sobre contratos administrativos de suministro y prestación de servicios. Diario Oficial, 30 de julio de 2003.

D.F.L. No 1 del Ministerio de Hacienda, Fija el texto refundido, coordinado y sistematizado de la ley orgánica del Consejo de Defensa del Estado. Diario Oficial, 7 de agosto de 1993.

D.F.L. No 1/19.653 del Ministerio Secretaría General de la Presidencia, fija texto refundido, coordinado y sistematizado de la Ley No 18.575 orgánica constitucional de bases generales de la administración del Estado. Diario Oficial, 17 de noviembre de 2001.

D.F.L. No 1 del Ministerio del Interior, fija el texto refundido, coordinado, sistematizado y actualizado de la Ley No 19.175, orgánica constitucional sobre gobierno y administración regional. Diario Oficial, 8 de noviembre de 2005.

D.F.L. No 7 del Ministerio de Hacienda, fija texto de la ley orgánica del Servicio de Impuestos Internos y adecua disposiciones legales que señala. Diario Oficial, 15 de octubre de 1980.

Decreto No 2421 del Ministerio de Hacienda, fija el texto refundido de la ley de organización y atribuciones de la Contraloría General de la República. Diario Oficial, 10 de julio de 1964. 
